$\mathcal{G S}_{\text {https://doi.org/10.3765/sp.14.9 }}^{\text {Semantics \& Pragmatics Volume 14, Article 9, } 2021}$

This is an EARLY ACCESS version of

Wilson, E. Cameron. 2021. The most, the fewest and the least: On the relative readings of quantity superlatives. Semantics and Pragmatics 14(9). https: //doi.org/10.3765/sp.14.9.

This version will be replaced with the final typeset version in due course. Note that page numbers will change, so cite with caution. 
EARLY ACCESS

\title{
The most, the fewest and the least: On the relative readings of quantity superlatives *
}

\author{
E. Cameron Wilson \\ Leibniz-Zentrum Allgemeine \\ Sprachwissenschaft (ZAS)
}

\begin{abstract}
This paper makes the empirical observation that so-called 'NP-internal relative readings' are available for certain speakers of English (as well as Dutch) for quantity superlatives but never for superlatives of other gradable adjectives. Previous accounts of this phenomenon in other languages attribute the availability of this type of reading to the absence of a definite article or DP layer. Contra the predictions of such accounts, in English, it is when the nominal expression containing the quantity superlative appears to be definite that these readings are generated. I account for these readings by building on the theory that many/much and their antonyms are fundamentally degree-predicates of scalar intervals, not degreepredicates of individuals. This leads me to propose a novel syntactic configuration in which the definite article forms a measure phrase constituent with the quantity superlative to the exclusion of the focused element. The NP-internal relative reading is derived through focus-association, with the superlative morpheme remaining in situ inside the definite measure phrase. The proposal adds to an emerging consensus that the quantity expressions much, many, few and little and their crosslinguistic counterparts are of a distinct type and are syntactically more complex than other gradable adjectives. It also provides indirect support for an in situ approach to deriving the relative readings of superlatives in definite contexts.
\end{abstract}

Keywords: superlatives, relative readings, quantity adjectives, definite article, DP structure

* This paper builds on research published in the proceedings of Sinn und Bedeutung 20 (Wilson 2015) and developed in my dissertation (Wilson 2018). This version contains additional evidence from English and Bulgarian, and the analysis has been revised to treat measure phrases as properties of scalar intervals rather than individuals. The explanation for differences between Bulgarian and English is also expanded and clarified. This work has been greatly enhanced by discussion with Sam Alxatib, Bill McClure, Jon Nissenbaum, Koen Roland, Uli Sauerland, Yael Sharvit, Stephanie Solt and others. I am very grateful to the editors and reviewers at Semantics and Pragmatics for their valuable comments and suggestions, and especially to my Bulgarian and Dutch informants, Venci Petkova, Vlada Stoyanova, Dora Valkanova, Tim Renders and Bob van Tiel. All errors are my own. 


\section{Introduction}

This paper examines a previously overlooked reading of quantity superlatives in English (the superlative forms of the quantity words many, much, few and little). I will show that these behave differently from the superlatives of ordinary adjectives in ways that have important consequences for our understanding of the extended NP structure and the analysis of superlatives in general.

The truth conditions of sentences containing superlatives are famously sensitive to context and prosody. This is illustrated by the sentence in (1). Out of the blue and with neutral prosody, the salient reading is the 'absolute' reading: that Annick picked the biggest one of all the apples in Brandenburg.

(1) Annick picked the biggest apple in Brandenburg.

In the context of Annick picking apples in various places, focus on Brandenburg gives rise to a 'relative' reading, true if she picked a bigger apple there than she did in any other state. When multiple apple pickers are salient, focus on the subject gives rise to a different one, true if Annick picked a bigger apple than anyone else did.

Quantity superlatives also have multiple relative readings, parallel to those available for biggest. Focus on the adjunct in (2) yields a comparison between the quantity Annick picked in Brandenburg versus other locations, while focus on Annick yields a comparison between quantities picked by her versus other relevant people.

(2) Annick picked the most apples in Brandenburg.

Competing accounts for these phenomena have been proposed by Heim (1985, 1999, 2000), Szabolcsi (1986, 2012), Farkas \& Kiss (2000) and Sharvit \& Stateva (2002), and more recently by e.g., Coppock \& Beaver (2014) and Bumford (2017). For the most part, the cases examined involve focus on a constituent external to the superlative DP. In this paper I discuss an additional relative reading that can arise in English when the focus pitch-accent is internal to the superlative DP. For example, if focus in (2) is on apples the sentence may be interpreted as comparing the quantities of different types of fruit that Annick picked in Brandenburg.

The parallel between (1) and (2) is one motivation for a tradition in the literature going back to Bresnan (1973) and Hoeksema (1984) of treating these quantity words as adjectival, that is, as gradable predicates of individuals. Hackl (2009) provides further support for such an approach by showing that it can be extended to derive the majority/'more-than-half' reading of most illustrated in (3).

(3) Worms destroyed most (of the) apples in the orchard. 
While the simple, adjectival treatment of most, least and fewest is conceptually appealing, I will argue that it is incompatible with the full range of relative readings that these quantity superlatives generate. In particular, it cannot account for the contrast which I describe below, between these superlatives and the superlatives of 'ordinary' adjectives in terms of the availability of 'NP-internal relative' readings. I argue instead for a more decompositional account of their meanings, treating them as predicates of type $\langle d,\langle\langle d, t\rangle, t\rangle\rangle$ and incorporating a silent measure function along the lines of Schwarzschild (2006) and Solt (2009, 2014). Such a decompositional approach to most is also advocated by Coppock et al. (2020).

\subsection{Relative readings with NP-internal focus}

The relative readings illustrated in (1) are triggered by focus on a constituent that is external to the superlative NP. Pancheva \& Tomaszewicz (2012) and Tomaszewicz (2015) describe a class of relative readings in Slavic languages which are triggered by focus within that NP, below the superlative modifier. What has previously been overlooked is that something like this 'NP-internal relative' reading is also available in English for many speakers, but only for superlatives of quantity (most, least, fewest). ${ }^{1}$ This reading is illustrated in (4), where capitalization indicates a focus pitch-accent on the adjective. In my own variety of English, this sentence clearly compares the number of green apples Ayşe picked to the numbers of apples of other colors that she picked - the NP internal relative reading. By contrast, the equivalent sentence in (5) with a non-quantity superlative is infelicitous and the NP-internal reading is simply unavailable. ${ }^{2}$

(4) Ayşe picked the most GREEN apples.

'Ayşe picked more green apples than any other kind of apple.'

1 Pancheva \& Tomaszewicz (2012) mention that the reading is 'marginally' available with quantificational superlatives in English, but their analysis predicts it to be unavailable. Shen $(2014,2015)$ and Tomaszewicz (2015) only address the absence of the reading for non-quantity superlatives.

2 The focus in (5) is not uninterpretable. It is possible to interpret (5) with either an absolute reading or an external relative reading with additional contrastive stress on green. For example, it is felicitous as a correction to (ia), limiting the domain to only green apples.

(i) a. AYŞE picked the biggest apples.

b. No, she picked the biggest GREEN apples, but Annick's red apples were even bigger than her green apples. 
(5) Ayşe picked the biggest YELLOW peaches.

\#‘Ayşe picked bigger yellow peaches than any other kind of peach.'

Informal investigation suggested that the availability of this reading for quantity superlatives is subject to interspeaker variation. Therefore a short survey was distributed by email and completed by 18 native English speakers from a range of dialect backgrounds. For each item, participants were given a scenario designed to be true on the NP-internal reading and false on both NP-external and absolute readings. They were given the choice between 'True' 'False' and 'Can't say-doesn't make sense'. For the sentence in (5) the scenario was as follows: Ayşe went to an orchard to pick peaches. She picked peaches of 3 varieties: white peaches, yellow peaches and doughnut peaches. There were a few really huge yellow peaches at the top of the trees but Ayse couldn't reach those so she left them. The doughnut peaches were quite small. The white peaches were larger, the size of baseballs. The yellow peaches that she picked were even larger, like giant softballs, though not as big as the ones she couldn't reach at the top. Is the following sentence true? "Ayse picked the biggest YELLOW peaches."

Seventeen respondents answered 'False' and one chose 'Can't say-doesn't make sense.' In other words, participants behaved quite uniformly in rejecting the internal relative reading of a non-quantity superlative.

The responses to the items with quantity superlatives were quite different. Here is one such scenario: Ayşe went to a different part of the orchard to pick apples. She picked apples of 3 varieties: red, golden and green. The trees were overflowing - there were hundreds of apples of each color in the orchard. There were also other people in the orchard who picked more apples of each color than Ayşe did. Ayşe herself picked 10 red apples, 20 golden apples and 30 green apples. Is the following sentence true? "Ayşe picked the most GREEN apples.". Again, the proportional reading and the external relative reading with focus on the subject are both clearly false. Only the internal relative reading with the focus on green is true.

For this item, only 7 respondents chose 'False' while 7 agreed with the author's intuition, judging the sentence 'True' on the internal relative reading. The remaining 4 chose 'Can't say-doesn't make sense.' Based on this survey, it appears that the phenomenon of internal relative readings is limited to North American varieties of English. 46\% (6/13) of North American respondents accepted (4) as true, and 53\% (7/13) accepted the variant (6a) in a similar context also designed to allow only the internal relative reading. British and Australian respondents generally did not accept the internal relative readings.

The internal relative readings can be generated not only by a focused adjective, but also by focus on another NP-internal constituent. Examples include focus on the head noun itself, on an NP-adjunct or on a complement of the noun, as in (6). 
(6) a. Ayşe picked the most APPLES.

'Ayşe picked more apples than any other fruit.'

b. She read the most books by ASIMOV.

'She read more books by Asimov than by any other author.'

c. She liked the most pictures of FLOWERS.

'She liked more pictures of flowers than pictures of anything else'

In English, most is ambiguous between being the superlative of the cardinal quantity word many and the mass quantity word much. As one reviewer points out, because much and its comparative and superlative forms can be used adverbially, this leaves open the possibility that the most in the above examples is not quantifying over apples as part of the DP, but is an adverbial modifier quantifying over picking events in the denotation of the VP. However, it is clear that the fewest, can only quantify over apples and has no adverbial use. (7) shows that fewest can be used in this construction and also gives rise to the NP-internal relative reading.

(7) Ayşe picked the fewest RED apples.

'Ayşe picked fewer red apples than any other kind of apple.'

Indeed, two additional respondents to the survey who rejected the variant with most accepted an NP-internal reading of fewest in the appropriate scenario-bringing the total proportion of North Americans who accepted some form of NP-internal relative readings to $62 \%$.

Finally, a word about argument position is in order. Relative readings of qsuperlatives are generally degraded in subject position (Farkas \& Kiss 2000, Kotek et al. 2011). This is true of NP-internal relative readings as well. This and other syntactic constraints are discussed in section 4.2, where I show that they are in fact predicted by my account. In the meantime I focus on constructions in which the superlative DP is the direct object of the verb.

\subsection{Comparison to Slavic}

NP-internal relative readings are available across Slavic languages. However, the phenomenon in these languages patterns quite differently than in English. Pancheva \& Tomaszewicz (2012) observe that in Bulgarian the NP-internal relative reading is equally available for quantity superlatives (8) and non-quantity superlatives (9) (their examples 18 and 17 respectively). 
(8) Ivan se zapozna s naj-mnogo studenti ot LONDON. Ivan REFL met with SUP-many student.PL from London. 'Ivan met more students from London than he did from any other city.'

(9) Ivan se zapozna s naj-mladi studenti ot LONDON. Ivan REFL met with SUP-young student.PL from London. 'Ivan met younger students from London than he did from any other city.'

However, when the definite marker $(-a t)^{3}$ is added, the NP-internal reading is no longer available in either case. The pitch-accent on London in (10) and (11) (ibid., examples 22 and 21) can only be interpreted as contrastive focus (see fn. 2).

(10) Ivan se zapozna s naj-mladi-te studenti ot LONDON Ivan REFL met with SUP-young-DEF student.PL from London. \#'Ivan met younger students from London than he did from any other city.'

(11) Ivan se zapozna s naj-mnogo-to studenti ot LONDON Ivan REFL met with SUP-many-DEF student.PL from London. \#'Ivan met more students from London than he did from any other city.'

This contrasts with English, in which adjectival superlatives must generally be preceded by a definite article in order to be grammatical. The rare sentences in which adjectival superlatives do appear in indefinite DPs do not have relative readings. For example, Herdan \& Sharvit (2006) observe that a sentence like (12a) is felicitous in a context where each class has one student who is better than all the others in that class. Yet (12b) does not have the reading that the class has a chemistry student who is better than students of any other major:

(12) a. This class has a best student.

b. This class has a best CHEMISTRY student.

The situation with non-definite marked most, least and fewest is more complex. Generally, bare most is associated with the majority reading illustrated in (3), and since there is no equivalent 'minority' reading (Hackl 2009) the bare forms of fewest and least are unacceptable as noun modifiers. There is experimental evidence that suggests that relative superlative readings are latently available to speakers alongside

3 The definite marker is suffixed to the first prosodic word of a DP in Bulgarian, and its form is determined by that of the word is attaches to (Franks (2001) and references therein, Embick \& Noyer (2001), Dost \& Gribanova (2006)). 
the majority reading of most of the (Kotek et al. 2015) - specifically in subject position where the non-partitive definite q-superlative is judged ungrammatical. Other authors have claimed that relative readings are in fact available with bare quantity superlatives in object position as well, (Szabolcsi 2012). However, the relevant examples for both external and internal relative readings in (13) are quite degraded.

(13) a. \%AYŞE picked most green apples.

b. \#Ayşe picked most GREEN apples.

To the extent that these readings of bare most are possible for some speakers, it seems likely that elision of a semantically active definite article is involved. I will briefly return to this issue in section 3.2.

The pattern of relative readings in Bulgarian and English shown in the table below, which illustrates the different interaction of definiteness with type of superlative in the two languages.

(14) Definite vs. Indefinite Superlatives

NP-external rel. NP-internal rel.

\begin{tabular}{lcc}
\hline BULGARIAN Definite & & \\
Q-superlatives (naj-mnogoto NP) & $\checkmark$ & $\#$ \\
Non-Q superlatives (naj-mladite NP) & $\checkmark$ & $\#$ \\
\hline BULGARIAN Indefinite & & $\checkmark$ \\
Q-superlatives (naj-mnogo NP) & $\checkmark$ & $\checkmark$ \\
Non-Q superlatives (naj-mladi NP) & $\checkmark$ & \\
\hline ENGLISH Definite & & $\checkmark$ \\
Q-superlatives (the most NP) & $\checkmark$ & $\#$ \\
Non-Q superlatives (the biggest NP) & $\checkmark$ & \\
\hline ENGLISH Indefinite & & $\#$ \\
Q-superlatives (most NP) & $\#$ & $\#$ \\
Non-Q superlatives $((a)$ biggest NP) & $\#$ & \\
\hline
\end{tabular}

The behavior of English q-superlatives is exceptional. It is only these that generate NP-internal relative readings in English and they do so when preceded by the definite article — in contrast both to English non-quantity superlatives and to Bulgarian superlatives in general. While I mostly focus on English in what follows, in section 6 we will see that certain definite-marked q-superlatives also have this reading in Flemish. 


\subsection{Summary}

Existing work on the phenomenon of NP-internal relative readings has focused on capturing the contrast between Slavic definite and indefinite DPs, and the contrast between English and Slavic adjectival superlatives. But an analysis of the English data must account for the availability of NP-internal readings for quantity superlatives when they follow the definite article. At the same time it should exclude these readings for adjectival superlatives in English. This paper gives an account that meets these criteria and makes additional predictions that are born out.

In the next section I review two accounts for the absence of NP-internal relative readings for adjectival superlatives in English. I show that both of these incorrectly predict that the NP-internal relative readings of quantity superlatives in English should also not be possible. I then discuss evidence of syntactic and semantic differences between adnominal quantity adjectives and other adjectives, as well as recent proposals that adnominal q-adjectives are introduced by a silent functional head in the extended projection of the NP.

In section 3 I provide an account for the unexpected relative readings. This is based on a novel syntax along with an interval-based approach to the semantics of quantity expressions that is inspired by Schwarzschild (2006) and Solt (2009, 2014). In section 4 I discuss two potential problems: first a counter-example to the claim that non-q-adjectives are not degree predicates of scalar intervals, and second the failure of subject DPs containing q-superlatives to generate NP-internal relative readings. In both cases we will see that the data are consistent with the account given in section 3. In section 5 I discuss the implications of this proposal for the 'SUP-in situ' versus 'SUP-movement' debate, especially with respect to 'upstairs de dicto' readings of superlatives. Section 6 addresses the question of cross-linguistic variation-the contrast between Bulgarian and English, and additional evidence from Flemish Dutch which is strikingly similar to English. Section 7 concludes.

\section{Relative readings of ordinary superlatives and quantity superlatives}

\subsection{Preliminaries}

Following the tradition of Cresswell (1976), von Stechow (1984, 2006), Kennedy (2001) and others, I assume that gradable predicates make reference to scales. For a given dimension, DIM, a scale, $S_{\text {DIM }}$, consists of a set of degrees of type $d$ and an ordering on that set $\left\langle\mathrm{D}_{d}, \leq_{\text {DIM }}\right\rangle$. A gradable adjective introduces a function $\mu_{\text {DIM }}$ from degrees on a particular scale to properties of individuals. As illustrated for big in (15), the degree that saturates the adjective's first argument is presupposed to belong to the relevant scale, though for brevity I omit this in what follows. 
The most, the fewest and the least

$$
\llbracket \operatorname{big} \rrbracket=\lambda d \lambda x: d \in S_{\mathrm{SIZE}} . d \leq \mu_{\mathrm{SIZE}}(x)^{4}
$$

The superlative morpheme takes a comparison class, C, as its first argument, then a degree predicate, and finally an individual argument (or an argument of whatever type the comparison class contains), as in (16) (Heim 1999).

$$
\begin{aligned}
& \llbracket \mathrm{SUP} \rrbracket=\lambda C_{\alpha t} \lambda R_{d, \alpha t} \lambda x_{\alpha}: x \in C \wedge \exists y \in C[y \neq x] \wedge \forall y \in C[\exists d[R(d)(y)]] \\
& . \exists d[R(d)(x) \wedge \forall y \in C[y \neq x \rightarrow \neg R(d)(y)]
\end{aligned}
$$

$\mathrm{C}$ is constrained by the presupposition that everything it contains can be mapped to some degree by the degree predicate. The superlative also carries the presupposition that the comparison class contains the external argument and at least one element that is distinct from it. If defined, the resulting expression asserts of an individual that it reaches a certain degree on the ordering encoded by the predicate that no other individual in the comparison class reaches. Finally, I adopt a standard definition of the definite article in (17). ${ }^{5}$

$$
\llbracket \text { the } \rrbracket=\lambda P .1 x . P(x)
$$

Where $\imath x . P(x)$ is defined iff $\exists x[P(x)]$ and, if defined, picks out the unique individual such that $P(x)=1 \wedge \forall x^{\prime}\left[P\left(x^{\prime}\right) \rightarrow x^{\prime} \sqsubseteq x\right]$

Accounts of superlatives differ with respect to the derivation of relative readings, but they generally agree on how absolute readings are derived (Heim 1999). The superlative morpheme moves minimally within the DP to take scope over the adjective-noun complex as in (18). Here, $\mathrm{C}$, is constrained by the presuppositions of SUP and by the discourse context to be a set of relevant apples. The superlative composes with the NP have the truth conditions in (19).

$$
\begin{aligned}
& \left.\left.\left.\left[I P \text { Ayşe picked [DP the [NP2 SUP-C [ } 1\left[N P 1\left[{ }_{D e g P} \mathrm{t}_{1} \text { big }\right] \text { apple }\right]\right]\right]\right]\right] \\
& \lambda x \exists d\left[\text { apple }(x) \wedge d \leq \mu_{\text {SIZE }}(x) \wedge \forall y \in C\left[y \neq x \rightarrow \neg\left[\operatorname{apple}(y) \wedge d \leq \mu_{\text {SIZE }}(y)\right]\right]\right]
\end{aligned}
$$

The definite article takes this superlative property and forms a referential expression that picks out the unique individual that satisfies it; the full proposition asserts that Ayşe picked that 'absolute' biggest apple.

4 While it is more conventional to put the measure function on the left and the degree variable on the right, I will generally give the equivalent formula with reversed order so as to emphasize that it denotes a set of degrees that comprise an interval ranging up to $\mu_{\mathrm{DIM}}(x)$.

5 The function of picking out a maximal individual is generally redundant in combination with superlative properties, since the superlative itself will have specified a property that can only be true of a unique/maximal individual before the definite article is merged, but the mereological basis of this morpheme that is captured by the relation $x^{\prime} \sqsubseteq x$ is important to the proposal in section 3 . 


\subsection{Relative readings of non-quantity superlatives}

It is in accounting for so-called relative readings that the proper treatment of superlatives continues to be debated. The relative readings of (20) are sensitive to focus and have weaker truth conditions than the absolute one.

(20) Ayşe picked the biggest apple yesterday.

With focal pitch-accent on Ayşe, the sentence may be judged true if she picked the largest apple out of a group of relevant people. If focus is switched to the adjunct, yesterday, the comparison is between the size of apples that Ayşe picked yesterday and those she picked on other relevant days. In neither case need she have picked the absolute largest apple.

\subsubsection{The in situ approach}

The 'SUP in situ' approaches ${ }^{6}$ (Heim 1999, Farkas \& Kiss 2000, Sharvit \& Stateva 2002) take the different readings to be primarily the result of context dependency, constrained by focus. What is being compared is always apples, but the subset of apples under consideration varies depending on context. As outlined by Heim (1999), the location of a focus operator plays an important role in disambiguation, and may require covert movement of the DP to create an appropriate constituent for this operator to scope over. This is shown in (21). The superlative morpheme itself remains inside the DP at LF.

$$
\left[\left[D P \text { the }\left[-C\left[1\left[\mathrm{t}_{1} \text { big apple }\right]\right]\right]\right]\left[\sim \mathrm{S}\left[I P 2\left[[\text { Ayşe }]_{F} \text { picked } \mathrm{t}_{2}\right] \text { yesterday }\right]\right]\right]
$$

As with the absolute readings, $\mathrm{C}$ is constrained by the SUP morpheme's presupposition in (22), but additional constraints are introduced by the covert focus operator $(\sim)$ (Rooth 1985). In order for this to be defined, C must be a subset of the grand union of the alternative set, S. This alternative set is constructed from the focus value of the IP that the operator merges with, as shown in (23). The conjunction of these presuppositions constrains the comparison class to contain only apples of some degree of size that were picked yesterday by either Ayşe or a relevant alternative to Ayşe.

$$
\mathrm{C} \subseteq\left\{x: \operatorname{apple}(x) \wedge \exists d\left[d \leq \mu_{\text {SIZE }}(x)\right]\right\}
$$

6 So called because the superlative morpheme does not raise out of the DP that contains it. It does move minimally within the DP to scope over the adjective-noun complex. 


$$
\mathrm{C} \subseteq \cup \mathrm{S} \subseteq \cup \llbracket \mathrm{IP} \rrbracket^{F}=\left\{\begin{array}{c}
x: \text { Ayşe picked } x \text { yesterday } \\
\vee \text { Annick picked } x \text { yesterday } \\
\vee \text { Alan picked } x \text { yesterday ... }
\end{array}\right\}
$$

The DP in (21) composes just as it would for the absolute reading. However, C does not include 'unpicked' apples. The DP refers to the unique apple that is largest just among those picked by relevant people, and the sentence is true just in case Ayşe picked that apple yesterday. $^{7}$

Other relative readings are derived based on the same LF, but with different comparison classes constructed depending on the location of focus. If focus is on yesterday, then the comparison class will contain only apples that Ayşe picked. The alternatives included in the set are those apples that she picked yesterday and those that she picked on relevant alternative days.

\section{Failure to generate NP-internal relative readings}

Pancheva \& Tomaszewicz (2012) show that the in situ derivation cannot compose when the superlative and the focus are both contained within a definite-marked DP. Here I summarize their reasoning using (5) (repeated here as (24)) as illustration.

Ayşe picked the biggest GREEN apple yesterday.

\#'Ayşe picked a bigger green apple yesterday than any other color of apple'

To generate the relative reading, the comparison class must include apples that Ayşe picked of various relevant colors. The problem is that there is no possible merge point for the focus operator that will generate an appropriate restriction on $\mathrm{C}$. The LFs in (25) represent two options for where to merge the focus operator. ${ }^{8}$

$$
\begin{aligned}
& \text { a. }\left[\sim \mathrm{S}\left[D P \text { the }[\mathrm{SUP}-\mathrm{C}] 1\left[\left[\mathrm{t}_{1} \mathrm{big}\right]\left[[\text { green }]_{F} \text { apple }\right]\right]\right] 2 \text { Ayşe picked } \mathrm{t}_{2}\right] \\
& \text { b. }\left[\left[D P \text { the }[\mathrm{SUP}-\mathrm{C}] \sim \mathrm{S}\left[{ }_{N P} 1\left[\left[\mathrm{t}_{1} \text { big }\right]\left[[\text { green }]_{F} \text { apple }\right]\right]\right]\right] 2 \text { Ayşe picked } \mathrm{t}_{2}\right]
\end{aligned}
$$

For focus association to succeed, the $\sim$ operator must scope over the focused constituent, but it must also be discontinuous with $\mathrm{C}$. If the operator is inserted in a high position as in (25a), then the derivation will crash because it contains a loop of infinite regress. The identity of the alternative set, $S$, depends on the focus value of a constituent that contains $\mathrm{C}$. But the value of $\mathrm{C}$ depends on the identity of S. Inserting

7 Sharvit \& Stateva (2002) observe that an additional effect of focus is the implicature that the predicate holds of no individual other than the focused one.

8 For a more thorough treatment including additional configurations which fail for the similar reasons to those outlined here see - altpancheva2012cross. I diverge from them in assuming that $\mathrm{C}$ and $\cup \mathrm{S}$ are in a subset relation rather than one of identity. 
it in a lower position, as in (25b), creates different problems. This configuration produces the comparison class in (26).

$$
\mathrm{C} \subseteq \cup \mathrm{S} \subseteq \cup[[\mathrm{NP}]]^{F}=\left\{\begin{array}{c}
x: \exists d x \text { is a } d \text {-big red apple } \\
\vee \exists d x \text { is a } d \text {-big green apple } \\
\vee \exists d x \text { is a } d \text {-big golden apple... }
\end{array}\right\}
$$

The first problem is that this $\mathrm{C}$ will not generate truth conditions that match the intuition that only those apples picked by Ayşe are being compared; because the VP is outside the scope of the focus operator, this component is not included in the restriction. The second problem is that the variation over alternative colors which is introduced via focus is essentially erased by the presuppositions of the superlative morpheme itself. As we saw for the NP-external reading above, the presuppositions are based on the (ordinary) value of the sister of SUP-C. So C must satisfy the following requirement in order for the expression to be defined:

$$
\mathrm{C} \subseteq\left\{x: \operatorname{green}(x) \wedge \operatorname{apple}(x) \wedge \exists d\left[d \leq \mu_{\mathrm{SIZE}}(x)\right]\right\}
$$

This precludes there being any colors of apples other than green in the comparison class. Whenever SUP-C scopes over the operator, the variation introduced by focus is cancelled, and the relative reading that depends on that focus is unavailable.

Below, I review the more widely accepted 'SUP-movement' account for relative readings of superlatives. Pancheva \& Tomaszewicz (2012) use this to derive the NP-internal relative readings of both quantity and non-quantity superlatives in the absence of definite marking in Slavic. They argue that this movement is unavailable whenever definite-marking is present. Indeed, I will show that the movement approach cannot derive the English pattern with NP-internal readings for definitemarked quantity superlatives.

\subsubsection{The movement approach}

The 'SUP-movement' approach (Szabolcsi 1986, Heim 1999) derives the variation in relative readings from syntactic ambiguity. The subject-relative reading of (20) compares not apples but people, asserting that Ayse is the one associated with the highest degree of apple-size picked yesterday. This is derived by the focused constituent raising to take clausal scope, and the superlative morpheme raising out of the DP to tuck in below it. The LF of the subject-relative reading of (20) on a movement derivation is shown in (28).

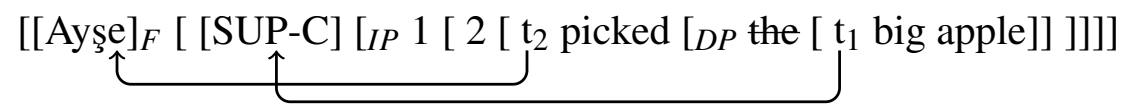


For English, this derivation depends in part on the assumption that the definite article is either vacuous or an allomorph of the existential operator. ${ }^{9}$ After predicate abstraction over both the individual and degree-arguments, the IP has the following denotation, which is the correct type for the superlative morpheme to take as its degree-predicate argument.

$$
[[\mathrm{IP}]]=\lambda d \lambda x \exists z \cdot \operatorname{picked}(z, x) \wedge \operatorname{apple}(z) \wedge d \leq \mu_{\mathrm{SIZE}}(z)
$$

The comparison class argument is constrained to be a set of individuals that can be mapped to some degree by this predicate. The superlative will combine with both of these arguments to return the property of being an individual that picked an apple reaching a higher degree of size than any other individual did. Finally the moved focused DP directly saturates the external argument, yielding the truth conditions in (31).

$$
\begin{aligned}
& \llbracket \text { SUP-C } \rrbracket(\llbracket I P \rrbracket)=\lambda x \cdot \exists d\left[\exists z \cdot \operatorname{picked}(z, x) \wedge \text { apple }(z) \wedge d \leq \mu_{\text {SIZE }}(z)\right] \\
& \wedge \forall y \in C\left[y \neq x \rightarrow \neg\left[\exists z \cdot \operatorname{picked}(z, y) \wedge \text { apple }(z) \wedge d \leq \mu_{\text {SIZE }}(z)\right]\right. \\
& \exists d\left[\exists z \cdot \operatorname{picked}(z, \text { a }) \wedge \operatorname{apple}(z) \wedge d \leq \mu_{\text {SIZE }}(z)\right] \\
& \wedge \forall y \in C\left[y \neq \mathrm{a} \rightarrow \neg\left[\exists z \cdot \operatorname{picked}(z, y) \wedge \text { apple }(z) \wedge d \leq \mu_{\text {SIZE }}(z)\right]\right.
\end{aligned}
$$

There is some degree such that Ayşe picked an apple that reaches that degree of size, and for no other relevant individual is it the case that they picked an apple that reaches that degree of size.

A persistent criticism of this approach is the exceptional treatment of the definite article as vacuous. Bumford (2017) provides a solution to this problem with a decompositional approach to the definite article, on which its two semantic functions (selecting an individual from a set and verifying the uniqueness of that individual) are evaluated at different points in the derivation. ${ }^{10}$ Another innovation of his approach is that the definite article composes directly with the superlative adjective. For reasons of space, I do not discuss this variant of the movement approach in detail here. In what follows I argue that only a quantity superlative may form a syntactic constituent with the definite article that is separable from the noun.

\section{Over/under-generation of NP-internal relative readings in DP-languages}

Pancheva \& Tomaszewicz (2012) argue that if the movement derivation were generally available, it would allow the unattested NP-internal relative readings to be

9 Szabolcsi (1986)'s original derivation has the move with the superlative morpheme (while the adjective stays low). But since these do not form a constituent, Heim (1999) and others since have assumed instead that the movement approach should treat the definite article as 'semantically vacuous' or else replaced by an existential quantifier.

10 See Coppock \& Beaver 2014, 2015 for another approach to this problem. 
derived in definite-marked constructions in English and Bulgarian. For this reason they assume that a definite D head creates a 'degree island', a constituent from which individuals and predicates of individuals may escape, but degree operators may not. A derivation based on extraction of the superlative is simply unavailable when the definite article is present. This means that only the in situ derivation is possible in these cases and, as we saw in the previous section, that can derive NP-external relative readings but not NP-internal ones. This, then, can explain the pattern of readings in Bulgarian, as well as the blocking of NP-internal relative readings for English non-q-superlatives.

Shen $(2014,2015)$ has an alternative account for the unavailability of a movement derivation for NP-internal relative readings in languages like English. On his account, this is because the DP in such languages is always a phase. The Phase Impenetrability Condition (Chomsky 2001) requires that extraction must always be through the edge of the phase. In (28) the subject is already external to the DP, and SUP-C may extract through Spec DP, leaving behind an intermediate trace on its way to tuck in below the raised subject. However, if the focused constituent is NP-internal, then it must extract through this phase edge, leaving its own intermediate trace in Spec DP. That position is therefore no longer free for SUP-C to move through (as indicated by $\left(* \mathrm{t}_{2}\right)$ in (32) and so the superlative cannot raise to scope over the clause.

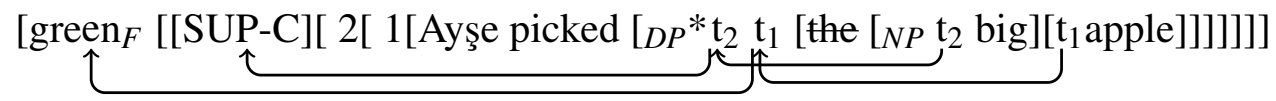

Shen argues that in article-less Slavic languages like Polish this double extraction is possible because the NP itself is a phase in the absence of a DP layer (Bošković 2008). In such languages, a focused NP-internal modifier is already at the phase edge, as is the superlative morpheme. Therefore they are both in a position to extract and do not have to compete for a single escape hatch.

[green $\underbrace{}_{F}\left[[S U P-C]\left[2\left[1\left[\right.\right.\right.\right.$ Ayşe picked [NP $\left[\mathrm{t}_{2}\right.$ big $]\left[\mathrm{t}_{1}\right.$ apple $\left.\left.\left.\left.]\right]\right]\right]\right]]]$

The fact that NP-internal relative readings are possible in Bulgarian (a 'DPlanguage') is surprising on this account. However, Talić (2020) has argued it is not the case that individual languages have only bare NP or full DP structure across the board. In particular, languages such as Bulgarian that have affixal definite articles exhibit evidence for both structures. She shows that, in the absence of overt definite marking, nominals in these languages pass the diagnostics for 'NPlanguages', for example allowing left-branch extraction, whereas in the presence of overt definite marking they behave like 'DP-languages.' Such an approach predicts that the extraction of two elements from the noun phrase is possible in Bulgarian 
when there is no overt definite marker: the NP is a phase in this case and the modifiers are already at the phase edge, just as in other Slavic languages.

The phenomenon of NP-internal relative readings provides its own test for Tali"s hypothesis. Shen (2014) observes that whenever NP itself is a phase, the anti-locality constraint blocks extraction of noun-complements. This explains the failure of his Polish example (34) to generate an NP-internal reading:

(34) Iwan poznal naj-mlodszych studentow [lingwistyki $]_{F}$.

Ivan met SUP-young students linguistics-GEN.

'Ivan met the youngest students of linguistics.'

\#'Among the students that Ivan met, the youngest are of linguistics.'

If Bulgarian, too, has a bare NP-structure for indefinites, then it is predicted that NP-internal relative readings should not be generated in these cases. Based on judgements from three Bulgarian informants, this prediction is born out. Focus on the complement of the noun modified by inteligentni in (35) does not generate an NP-internal reading.

(35) Ivan poznava naj-inteligentni učenitsi po [biologija $]_{F}$. Ivan knows SUP-smart.PL students of biology. \#Ivan knows smarter students of biology than students of other subjects.

Assuming that there is indeed no DP-layer at all in Bulgarian indefinite NPs, then the availability of NP-internal relative readings in these constructions is unsurprising. Meanwhile, it is predicted that the derivation will be blocked in Bulgarian when there is an overt definite suffix (the DP whose presence is signaled by this element is a phase, and the double extraction through its edge is impossible, just as in English). In combination with Talić's hypothesis that Bulgarian is an intermediate NP/DP-language, Shen's account of the constraints on SUP-movement can cover the pattern of available readings in that language, as well as the absence of NP-internal relative readings for English non-q-superlatives. According to this approach, English NP-external relative readings may be derived by SUP-movement, while on P\&T's approach, English relative readings may only be derived by focus-association with SUP in situ. Importantly, a simple extension of either account to quantity superlatives in English leads to the wrong predictions, as we will see below.

\subsection{Relative readings of quantity superlatives}

Following Hackl (2009), Pancheva \& Tomaszewicz (2012) assume that many has the denotation in (36) where $\mu_{\#}$ stands for a measure function that maps an individual 
sum to the degree on the cardinality scale that corresponds to the number of atoms it is made up of. This is in line with a tradition in the literature that goes back to Bresnan (1973) and Hoeksema (1984).

$$
\llbracket \text { many } \rrbracket=\lambda d_{d} \lambda P_{e t} \lambda x_{e} \cdot P(x) \wedge d \leq \mu_{\#}(x)
$$

The approach works neatly for the pattern observed in Slavic languages. Since quantity superlatives and adjectival superlatives are basically of the same type, they will be subject to the same syntactic constraints. The availability of NP-internal relative readings in indefinite but not definite DPs is therefore predicted for quantity superlatives.

The pattern for English is quite different, and quantity superlatives do not behave as predicted. As we have discovered, the NP-internal relative reading is in fact available just in case the definite article is present. The following table repeats the English data from (14) that requires explanation:

$$
\text { Relative readings of definite DPs in English }
$$

NP-external rel. NP-internal rel.

Definite

Q-superlatives (the most NP)

Non-Q superlatives (the biggest NP)

If many and its kin are given an adjectival treatment in English, then the NP-internal relative reading for definite-marked the most NP is predicted to be unavailable. The reading cannot be generated on an in situ derivation because there is no way to create the right kind of constituent to merge the focus operator with. The movement approach has the problem of the single 'escape hatch' which prevents the superlative morpheme and the focused element from both extracting out of the DP phase. Hence, if we take an adjectival approach to quantity words as in (36), the pattern in Table 3 should not be possible. The English data on NP-internal readings is better understood in the context of approaches that treat q-adjectives as a different kind of gradable expression, discussed below. ${ }^{11}$

11 There are, of course, a number approaches to most, least and their ilk, the most famous of which is the Generalized Quantifier Theory of Barwise \& Cooper (1981). See Wilson 2018 for additional discussion of the alternatives and Coppock et al. (2020) for a recent overview of this literature. 


\subsection{Differences between quantity and non-quantity adjectives}

As Solt $(2009,2014)$ observes, many, much, few and little have a much wider distribution than 'ordinary' adjectives. Even as in their most adjective-like use as noun modifiers, they show evidence of an underlyingly different syntactic structure. Schwarzschild (2006) has linked these syntactic differences to a significant semantic difference between q- and non-q-adjectives with respect to measure-monotonicity. Evidence for the distinct syntax and semantics of q-adjectives is reviewed in this subsection. This will form the foundation on which my proposal for deriving relative readings of q-superlatives is built.

\subsubsection{Syntactic differences}

First let us consider the syntactic differences that set many, few, much and little apart from other gradable adjectives, even on their adnominal uses. Kayne (2005) observes that, while adjectives generally cannot stand alone as arguments, q-adjectives may, and indeed are incompatible with pronominal one:

(38) a. Ayşe picked big apples but Annick picked small ones/*small.

b. Ayşe picked many apples but Annick picked *few ones/few.

In adnominal position, the phrase containing much/many is also syntactically more independent from the noun than an adnominal adjective phrase. In (39b) and (39c), we see that either the quantity word (and its modifier) or the lower portion of the NP can be pseudoclefted. Interestingly, when they are separated in this way, of is pronounced as part of the remnant NP in the lower position, although it is absent in the unclefted construction (39a). ${ }^{12}$

12 A reviewer observes that with the superlative most, the constituent green apples can be pseudoclefted without pronouncing the of, as in (i)a, while the equivalent construction with many (i)b is impossible. This follows if (i)a is based on an adverbial construction which is incompatible with non-adverbial many. Notice that (unambiguously non-adverbial) the fewest is also unacceptable in (i)c.

(i) a. It is GREEN apples that Ayşe picked the most yesterday

b. *It is GREEN apples that Ayşe picked many yesterday

c. *It is GREEN apples that she picked the fewest yesterday. 
(39) a. Ayşe picked that many green apples yesterday.

b. It was green apples that Ayşe picked that many of.

c. It was that many that Ayşe picked of green apples.

The mysterious of that surfaces in (39) may be taken as evidence for the presence of the pseudopartitive (MonP) structure for many NP that Schwarzschild (2006) (following Jackendoff (1977) and others) proposes. In the last part of this section I discuss the semantic presupposition which, following Schwarzschild, I will assume is introduced by this additional functional layer.

\subsubsection{Semantic differences}

A crucial semantic difference between q-adjectives and non-q-adjectives concerns a higher-order property which has variously been identified as 'extensivity' (Krifka 1989), 'monotonicity' (Lønning 1987, Schwarzschild 2002, 2006) and 'stratified reference' (Champollion 2015) of a measure function with respect to its nominal domain. Adopting Schwarzschild's terminology, a monotonic measure is one that 'tracks' the (contextually relevant ${ }^{13}$ ) part-whole structure of the entity or entities in its domain. Formally, monotonicity can be defined as in (40):

$$
\text { Monotonic (P, DIM) iff } \forall x, y \in P . y \sqsubset x \rightarrow \mu_{\mathrm{DIM}}(y)<\mu_{\mathrm{DIM}}(x)
$$

If I have a pile of 'large apples', a proper sub-part of it that is still 'apples' will be one or two of those apples. Since 'large' is distributive, the subset will have the same degree of (per apple) 'largeness' as the whole. By contrast, if I have a pile of 'many apples' a proper sub-part of it will necessarily have a lower degree of 'manyness' than the whole. Hence, the cardinality measure is monotonic with respect to the domain of plural individuals, while the size measure introduced by an adnominal adjective such as 'large' is not.

Schwarzschild (2006) links the property of monotonicity to the syntax of partitive and pseudopartitive structures. He hypothesizes that the monotonicity requirement is introduced as a presupposition by a functional head, Mon, in the extended projection of NP. In pseudopartitive measure constructions (where the measure phrase is lexically headed by a unit noun) this is spelled out as of, as in five pounds of apples, whereas when quantity is expressed with a q-adjective the Mon head is silent. Solt (2009, 2015) builds on the idea of a silent Mon head, proposing that in addition

13 This proviso is important because measures such as length, width and depth are otherwise not monotonic on the mereological structure of three-dimensional entities. See Champollion 2017 for an implementation in terms of stratified reference that addresses this issue, and Wilson (2018) for an alternative based on the notion of dimensional parthood. 
to the presupposition, the measure function itself is introduced by this morpheme (which she labels MEAS), rather than by the q-adjective. This enables her to provide a unified treatment of much, many, little and few as degree quantifiers across all of their uses, and to account for certain split scope phenomena on their adnominal uses.

\section{Proposal}

The empirical landscape makes clear that the syntax and semantics of at least some varieties of English can generate the relative readings of definite-marked noun phrases containing quantity superlatives with NP-internal focus, as in (41). Yet this grammar cannot generate such relative readings for non-quantity superlatives, as in (42).

(41) Ayşe picked the most GREEN apples yesterday.

'Ayşe picked more green apples yesterday than any other kind of apple'

(42) Ayşe picked the biggest GREEN apples yesterday.

\#'Ayşe picked bigger green apples yesterday than any other kind of apple'

In this section I put forward a particular approach to many, few, much and little as quantity words and show how this makes possible a SUP-in situ derivation for their superlatives that gives rise to the NP-internal relative readings. I then explain why the same derivation is not possible with non-quantity superlatives in sentences like (42).

\subsection{Overview of the proposal}

I propose that NP-internal relative readings are generated for quantity superlatives in English precisely because they are not like ordinary adjectives. Rather than directly modifying the NP, many forms part of a separate subconstituent in a covert measure pseudopartitive structure. I adopt Schwarzschild (2006)'s analysis of measure pseudopartitives. While an attributive adjective introduces a degree variable into the derivation, Schwarzschild's Mon head introduces an interval variable. I diverge slightly from Schwarzschild's original proposal in that I assume the specifier of MonP directly saturates this argument. I also adopt an analysis of the quantity words many, much, few and little as degree predicates of intervals as proposed by Solt (2009, 2014).

What is novel on my account is that the definite article forms a subconstituent with the superlative q-adjective. This 'inner' DP refers to a unique scalar interval - something of type $\langle d, t\rangle$. The entire phrase, the most, can be extracted and raised into a configuration in which focus association can occur. While others have 
proposed constituency of the definite article with superlative adjectives across the board (Krasikova 2012, Bumford 2017), I assume such constituency is exclusively possible for q-superlatives. Non-quantificational superlatives, are merged directly with the NPs that they modify, as they are of the wrong type to participate in the pseudopartitive structure that allows the SUP-in situ derivation to compose with NP-internal focus.

The initial syntactic structure of the direct object in (41), the most GREEN apples, is given below. The definite article forms a constituent with the quantity superlative to the exclusion of the NP that bears focus (which I label $\mathrm{NP}_{\text {subs }}$ for 'substance NP' following Schwarzschild's terminology). The 'measure DP', the most in (43), is then merged as the specifier of the Mon head. The entire pseudopartitive NP is finally merged with a silent existential determiner to form the 'substance DP'.

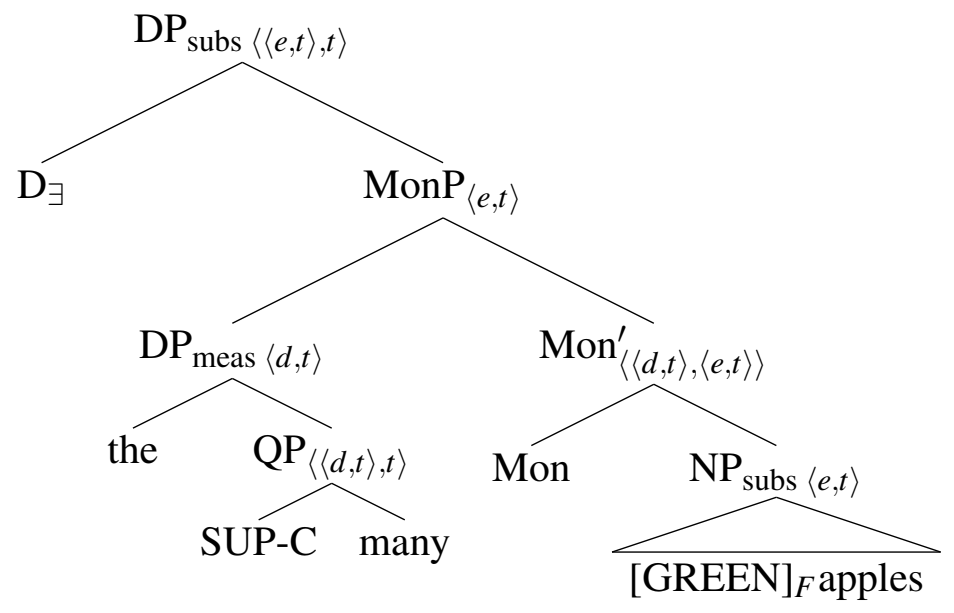

Recall that for the in situ derivation of NP-external relative readings to converge, the entire superlative-containing DP must raise to take clausal scope, creating a constituent for the focus operator to merge with. For NP-internal focus to compose, it is the measure DP that extracts from within the larger indefinite DP to create this constituent. As illustrated in (44) the focus operator can then merge to take scope over everything except the definite measure phrase which then re-merges above. 
The most, the fewest and the least

(44)

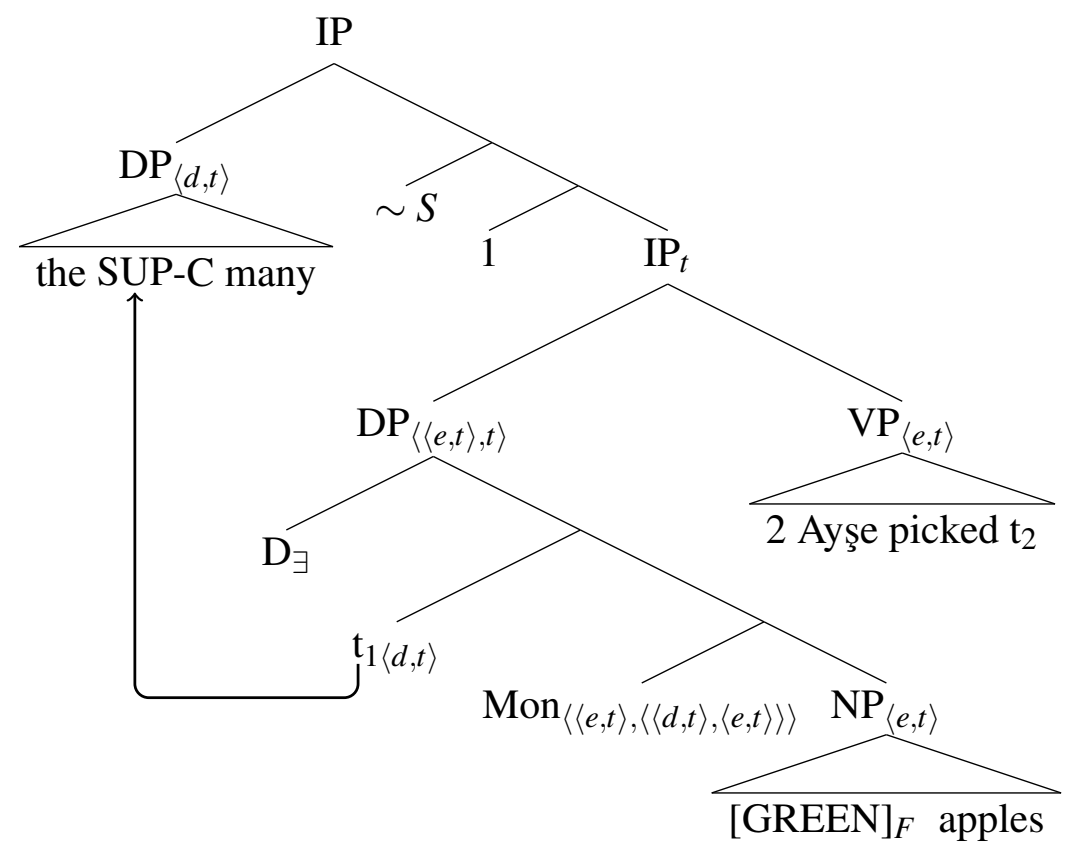

This SUP-in situ derivation gives rise to NP-internal relative readings for the quantity superlative. At the same time it leaves intact previous explanations for the lack of NP-internal relative readings with non-q-superlatives. In the next subsection I present the technical details of the proposal. I return to a more generalized discussion of the contrast to non-q-superlatives in section 3.3.

\subsection{Details of the proposal}

Implicit in Schwarzschild's system is the notion that scales (at least those that are monotonic) have their own mereological structure. For example, unit nouns denote sets of intervals that may be pluralized and combine with numbers just like individuals in the sets denoted by ordinary count nouns. Hence, there is something 'entity-like' about an interval introduced by Mon. I assume that determiners that make reference to mereological orderings may combine either with sets of individuals or sets of intervals, but not with sets of degrees, since these have only a total ordering and not a mereological part/whole ordering associated with them. ${ }^{14}$

14 For clarity, I distinguish between total orderings on degrees that structure scales and the partial ordering on intervals as segments of such scales by using angled symbols for the former $(<, \leq$,$) and$ squared symbols for the later $(\sqsubset, \sqsubseteq)$. 


\subsubsection{The MonP projection}

An essential component of this analysis is the Mon head. Schwarzschild identifies this as a functional morpheme in the extended projection of the noun phrase. It introduces an interval variable along with the presupposition of measure-monotonicity between the scale that the interval is part of and the extension of the NP with which it combines. I implement this by having the Mon head encode a function, $M$, parameterized for dimension, that maps an individual to the positive interval that corresponds to its extent on that dimension. The interval must be a segment of a scale for a dimension which is monotonic on the NP (with respect to the contextually relevant mereological structure of its extension).

$$
\begin{aligned}
& \mathrm{M}_{\mathrm{DIM}}(x)=\lambda d\left[d \leq \mu_{\mathrm{DIM}}(x)\right] \\
& \llbracket \mathrm{Mon} \rrbracket_{\mathrm{DIM}}=\lambda P_{e t} \lambda I_{d t} \lambda x_{e} .: \text { Monotonic }(P, \mathrm{DIM}) \wedge I \sqsubseteq S_{D I M} \\
& . P(x) \wedge \mathrm{M}_{\mathrm{DIM}}(x)=I
\end{aligned}
$$

Defined for a property of individuals, $P$, and an interval, $I$, just in case the interval is part of the scale of some dimension that is monotonic on $P$.

If defined, maps an interval to the property of being an individual in $P$ whose measure in DIM is equal to the interval $I$.

The MonP projection is part of the extended projection of NP, above attributive modifiers but below the DP.

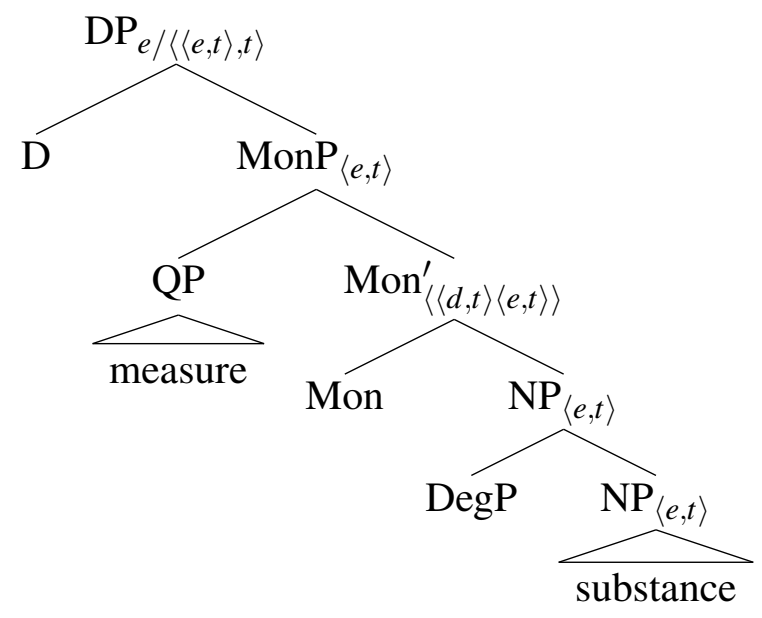

The QP in the specifier of MonP is filled by an argument of type $\langle d, t\rangle$ that denotes the scalar interval corresponding to the 'measure' of the substance in question. This may be a size expression, like a few inches which values Mon for the length dimension. It may instead be a quantity expression such as three, so many or the fewest, in which case Mon is valued for the cardinality dimension. 
The most, the fewest and the least

\section{Composition of the three apples}

Before considering superlative quantity words, let us observe how this system works for a DP containing a simple cardinal expression, as in (48).

(48) a. the three apples

b. $\quad[\mathrm{DP}$ the $[\operatorname{MonP}[\mathrm{QP}$ three $][\operatorname{Mon}[\mathrm{NP}$ apples $]]]]$

I represent the numeral three as in (49), as the interval of the cardinality scale ranging from zero to the degree 3, following a suggestion in Solt 2011.

$$
\llbracket \text { three } \rrbracket=\lambda d: d \in S_{\# . d} \leq 3
$$

The presuppositions of Mon will be satisfied by the plural NP apples. The cardinality scale is monotonic on the extension of apples, since for any group of apples that measures $I$, a subpart that is also apples will have a measure that is a sub-interval of $I$. Mon' composes with the cardinal interval denoted by three to give us (50).

$$
\llbracket \mathrm{MonP} \rrbracket_{\#}=\lambda x_{e} \cdot{ }^{*} \text { apple }(x) \wedge\left[\lambda d . d \leq \mu_{\#}(x)\right]=[\lambda d . d \leq 3]
$$

The set of sums of apples such that the interval from zero to their measure on the cardinality dimension is equal to the interval from zero to three.

The second conjunct of this is logically reducible to $\mu_{\#}(x)=3$. This MonP may merge with a definite or indefinite determiner. In our example, it combines with the definite article, whose denotation is repeated here for convenience. If the presupposition that there exists something that satisfies the MonP property is met, then this generates the DP in (51) that refers to the unique individual that is a sum of apples that the cardinality measure function maps to three.

$$
\begin{aligned}
& \llbracket \text { the } \rrbracket=\lambda P_{e t}: \exists x[P(x)] . \imath x\left[P(x) \wedge \forall x^{\prime}\left[P\left(x^{\prime}\right) \rightarrow x^{\prime} \sqsubseteq x\right]\right] \\
& \llbracket \mathrm{DP} \rrbracket=\imath x\left[{ }^{*} \operatorname{apples}(x) \wedge \mu_{\#}\left(x^{\prime}\right)=3 \wedge \forall x^{\prime}\left[{ }^{*} \operatorname{apples}\left(x^{\prime}\right) \wedge \mu_{\#}\left(x^{\prime}\right)=3 \rightarrow x^{\prime} \sqsubseteq x\right]\right]
\end{aligned}
$$

\subsubsection{Composition of the most}

Now let us consider the more complex derivation, where the most is merged in the specifier of MonP. As indicated at the beginning of this section, I assign the structure in (52) to this constituent. In this measure-DP, the $e$-type arguments of an ordinary DP are replaced with intervals of type $\langle d, t\rangle$. The entire measure DP is merged in 
the specifier of MonP, but extracts from under the existential quantifier that heads the substance DP, leaving behind a trace as in (53). The reader may observe that there is no type mismatch to force $D P_{\text {meas }}$ to raise. It is type $\langle d, t\rangle$ and $\mathrm{Mon}^{\prime}$ is type $\langle\langle d, t\rangle,\langle e, t\rangle\rangle$. However, I assume that such movement is freely available since there is nothing to block extraction out of the larger indefinite substance DP. As we will see, this movement is necessary because the DP cannot be interpreted at the point where it is merged.
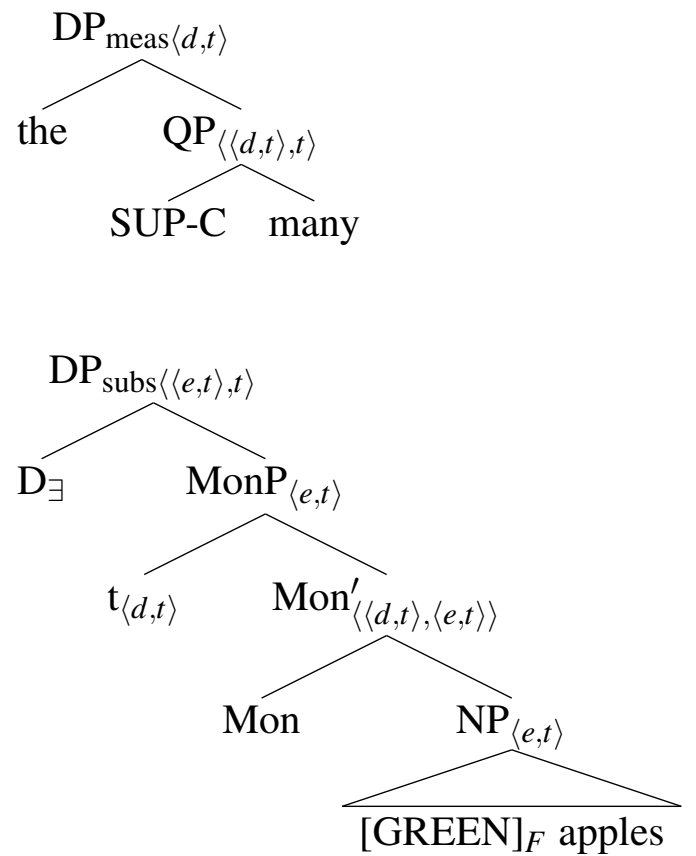

I follow Solt $(2009,2014)$ in representing quantity words as functions from degrees to sets of intervals. The lexical items much and little are under-specified for dimension, while many and few are specified for cardinality.

$$
\begin{aligned}
& \llbracket \text { much/many } \rrbracket=\lambda d_{d} \lambda I_{d t}: d \in D_{\mathrm{DIM}} \wedge I \sqsubseteq S_{\mathrm{DIM}} \cdot I(d) \\
& \llbracket \text { little/few } \rrbracket=\lambda d_{d} \lambda I_{d t}: d \in D_{\mathrm{DIM}} \wedge I \sqsubseteq S_{\mathrm{DIM}} \cdot \neg I(d)
\end{aligned}
$$

I have assumed that the superlative morpheme is type-flexible. In the following denotation its comparison class argument is a set of intervals, rather than a set of individuals, or properties thereof. ${ }^{15}$.

15 See Solt 2011 for such an approach to modified numerals 
The most, the fewest and the least

$$
\begin{array}{lr}
\left.\llbracket \mathrm{SUP} \rrbracket=\lambda C_{d t t} \lambda R_{d, d t t} \lambda I_{d t}: I \in C \wedge \forall J \in C \exists d[R(d)(J)]\right] & \text { (presupposition) } \\
. \exists d[R(d)(I) \wedge \forall J \in C[J \neq I \rightarrow \neg R(d)(J)] & \text { (assertion) }
\end{array}
$$

Once it has combined with the comparison class argument, the superlative takes a degree-predicate of intervals as its second argument. This is the type of many, so [SUP-C] can combine with the quantity-word directly to form the QP in (57).

$$
\llbracket \text { SUP-C-many } \rrbracket=\lambda I_{d t} . \exists d[I(d) \wedge \forall J \in C[J \neq I \rightarrow \neg J(d)]
$$

The definite article takes a set that is associated with a mereological ordering and returns the unique member of the set that is the sum of all its elements (just in case such an individual exists). As we have observed, intervals of a monotonic scale are in part-whole relationship with each other, so the definite article may be defined for sets of intervals with respect to this mereology. The interval-based denotation of the is given in (58). It composes with most as in (59).

$$
\begin{aligned}
& \llbracket \text { the } \rrbracket=\lambda D_{d t t} . l I\left[D(I) \wedge \forall I^{\prime}\left[D\left(I^{\prime}\right) \rightarrow I^{\prime} \sqsubseteq I\right]\right] \\
& \llbracket \text { the } \rrbracket(\llbracket \text { most } \rrbracket)=I I \in C\left[\forall I^{\prime}\left[\exists d\left[I^{\prime}(d) \wedge \forall J \in C\left[J \neq I^{\prime} \rightarrow \neg J(d)\right] \rightarrow I^{\prime} \sqsubseteq I\right]\right]\right]
\end{aligned}
$$

Whenever the comparison class is valued as a set of positive intervals, the measure DP the most will point to the unique interval that is the largest of these.

In order for this measure DP to be interpreted, the comparison class must be assigned a value. The comparison class argument cannot be valued by focus association without further movement. A focus operator must be inserted above where the individual argument of the substance DP is existentially closed in order to generate an alternative set of the right type (a set of sets of intervals). Hence the only interpretable derivation will be one in which the measure DP extracts and raises to take clausal scope above this operator. In the next subsection I describe how the remnant substance DP and the rest of the clause compose to have the appropriate denotations.

\subsubsection{Composition of IP and the comparison class}

With the measure DP extracted, the clause has the structure in (60). The max operator will be discussed below. The focus operator merges with an IP of type $\langle\langle d, t\rangle, t\rangle$ which is formed by predicate abstraction over the trace of the measure DP. In this configuration, the operator takes scope over the focused element, but is discontinuous with the comparison class argument of SUP, so focus association is successful. The conflict with presuppositions that blocks the in situ derivation of NP-internal readings of adjectival superlatives does not arise. 
$(60)$

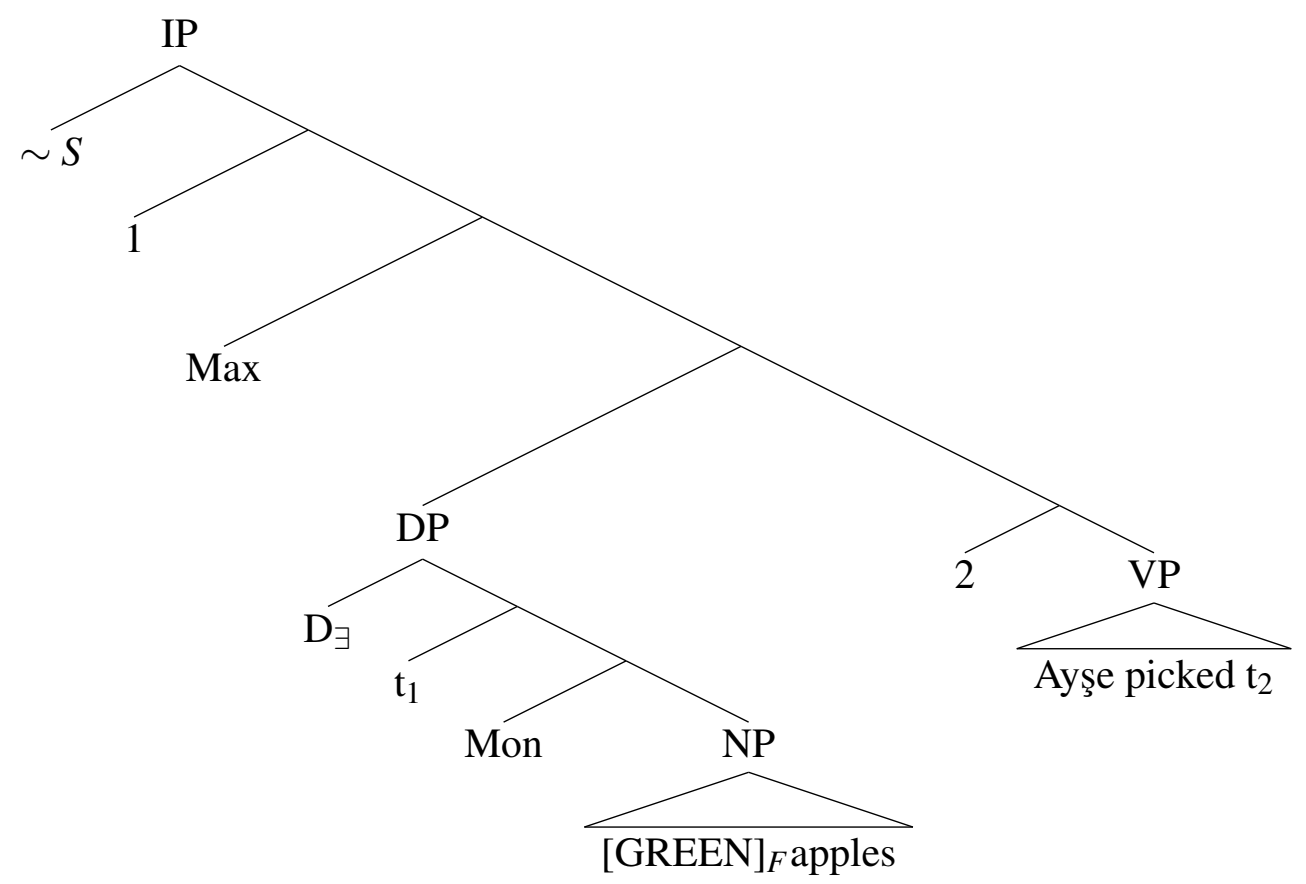

MonP composes as in three apples (50), with two differences. Instead of the interval $[\lambda d . d \leq 3]$, there is a trace of type $\langle d, t\rangle$. And secondly, the adjective GREEN is focused. In principle there are several dimensions that would satisfy the Monotonicity presupposition of Mon, but for simplicity I will again value it here as cardinality. This gives us the following ordinary value for MonP:

$$
\llbracket \operatorname{MonP}_{\#} \rrbracket^{O}=\lambda x_{e} \cdot{ }^{*} \text { green apple }(x) \wedge\left[\lambda d . d \leq \mu_{\#}(x)\right]=t_{1}
$$

The entire DP is indefinite, so the D head is filled with a silent existential determiner. The ordinary value of the DP is shown in (62).

$$
\llbracket \mathrm{DP} \rrbracket^{O}=\lambda P_{e t} \exists x_{e} \cdot * \text { green apple }(x) \wedge\left[\lambda d . d \leq \mu_{\#}(x)\right]=t_{1} \wedge P(x)
$$

This combines with the remnant IP containing the VP. After lambda extraction of the interval argument, the ordinary value of the IP is something of type $\langle\langle d, t\rangle, t\rangle$ with the value in (63).

$$
\llbracket \mathrm{IP} \rrbracket^{O}=\lambda I_{d t} \exists x_{e} \cdot{ }^{*} \text { green apple }(x) \wedge \operatorname{picked}(x, \mathrm{a}) \wedge\left[\lambda d . d \leq \mu_{\#}(x)\right]=I
$$

The focus value of this constituent is a set of sets of intervals: 
The most, the fewest and the least

$$
\llbracket \mathrm{IP} \rrbracket^{F}=\left\{\begin{array}{c}
\lambda I \exists x \cdot{ }^{*} \text { green apple }(x) \wedge \operatorname{picked}(x, \mathrm{a}) \wedge\left[\lambda d . d \leq \mu_{\#}(x)\right]=I \\
\lambda I \exists x .^{*} \text { red apple }(x) \wedge \operatorname{picked}(x, \mathrm{a}) \wedge\left[\lambda d . d \leq \mu_{\#}(x)\right]=I \\
\lambda I \exists x \cdot{ }^{*} \text { golden apple }(x) \wedge \operatorname{picked}(x, \mathrm{a}) \wedge\left[\lambda d . d \leq \mu_{\#}(x)\right]=I \ldots
\end{array}\right\}
$$

However, merging the squiggle operator at this point would not yield exactly the correct comparison class for the following reason. For concreteness, let us imagine the following scenario: Ayşe picked seven apples of color A, five of color B and three of color $\mathrm{C}$. The comparison class of intervals corresponding to their measures includes the intervals $[\lambda d . d \leq 3],[\lambda d . d \leq 4],[\lambda d . d \leq 7]$. It also includes every positive interval that is a sub-part of one of those, by virtue of the low scope of existential quantification and the fact that if Ayşe picked seven of one color apples then she necessarily also picked six of that color apples and so on. While this still leads to the correct truth conditions for the positive quantity words, this effect of the scope of the existential is a problem for negative quantity words. There is a more subtle issue that arises even with positive quantity superlatives. The focus operator comes with the requirement that its sister be a non-singleton set. This presupposition is in fact trivially satisfied even in the absence of focus alternatives because of the location of the existential quantifier. In the absence of focus, the set of intervals denoted by the IP is still a set of sets, since each individual interval is by definition itself a set of degrees. It has been argued previously that a maximality operator is needed for negative superlatives in general (Heim 2002, Hackl 2000, Sharvit \& Stateva 2002). By introducing such an operator and converting the alternatives to singleton sets, we ensure that the focus operator will only have its requirement met when focus is in fact present, and that it will combine with a set of singleton sets of intervals, rather than with a set of sets of degrees.

Buccola \& Spector (2016)'s silent Max operator ${ }^{16}$ is modified in (65) to work within my own assumption that measure phrases and their traces denote intervals, rather than degrees.

$$
\begin{aligned}
& \llbracket \operatorname{Max} \rrbracket=\lambda I_{\langle d, t\rangle} \lambda D_{\langle\langle d, t\rangle, t\rangle \cdot \max (D)=I} \\
& \text { where } \max (I)=\imath I . D(I) \wedge \forall I^{\prime}\left[D\left(I^{\prime}\right) \rightarrow I^{\prime} \sqsubseteq I\right]
\end{aligned}
$$

An additional movement of the measure phrase creates a clause-level trace to which this operator applies:

$$
\left[1\left[\operatorname{Max~}_{1}\right]\left[I P\left[D P \mathrm{D}_{\exists} \mathrm{t}_{1} \text { Mon green }{ }_{F} \text { apples }\right] 2\left[\text { Ayşe picked } t_{2}\right]\right]\right]
$$

16 In their account for upper bounded readings of modified numerals Buccola \& Spector (2016) compare a number of approaches to maximality. The 'SMax' approach adopted here involves an operator that is syntactically independent, but lacks the additional power of an informativity-based maximality which is not necessary for our purposes. 


$$
\llbracket \operatorname{Max} \rrbracket\left(t_{1}\right)=\lambda D_{\langle\langle d, t\rangle, t\rangle} \cdot \max (D)=t_{1}
$$

This converted trace combines with the IP as follows:

$$
\left.\llbracket \operatorname{Maxt}_{1} \rrbracket(\mathrm{IP})=\max \left(\lambda I \exists x .^{*} \operatorname{green} \operatorname{apple}(x) \wedge \operatorname{picked}(x, \mathrm{a}) \wedge M(x)=I\right]\right)=t_{1}
$$

Lambda extraction then produces a new property of intervals which is the singleton set containing the maximal interval of which the original IP held.

$$
\left.\llbracket \mathrm{IP}_{2} \rrbracket=\lambda I^{\prime} \cdot \max \left(\lambda I \exists x .{ }^{*} \text { green apple }(x) \wedge \operatorname{picked}(x, \mathrm{a}) \wedge \mathrm{M}(x)=I\right]\right)=I^{\prime}
$$

Now the focus value is a set of singleton sets of intervals:

$$
\llbracket \operatorname{IP}_{2} \rrbracket^{F}=\left\{\begin{array}{c}
\left.\lambda I^{\prime} \cdot \max \left(\lambda I \exists x \cdot{ }^{*} \operatorname{green}-\operatorname{ap}(x) \wedge \operatorname{picked}(x, a) \wedge M(x)=I\right]\right)=I^{\prime} \\
\left.\lambda I^{\prime} \cdot \max \left(\lambda I \exists x \cdot{ }^{*} \operatorname{red}-a p(x) \wedge \operatorname{picked}(x, a) \wedge M(x)=I\right]\right)=I^{\prime} \\
\left.\lambda I^{\prime} \cdot \max \left(\lambda I \exists x \cdot{ }^{*} \operatorname{golden}-\operatorname{ap}(x) \wedge \operatorname{picked}(x, a) \wedge M(x)=I\right]\right)=I^{\prime} \ldots
\end{array}\right\}
$$

At the point the squiggle operator is merged, and the comparison class is valued as the grand union of the alternatives in $\mathrm{S}$, as defined by the focus value of $I P_{2}$.

$$
\begin{aligned}
& C \subseteq \cup S \subseteq\left\{I^{\prime}: \max \left(\lambda I \exists P \in \left\{{ }^{*} \text { green-ap, }{ }^{*} \text { red-ap, }{ }^{*}\right.\right. \text { golden-ap... }\right. \\
& \left.. P(x) \wedge \operatorname{picked}(x, \mathrm{a}) \wedge M(x)=I)=I^{\prime}\right\}
\end{aligned}
$$

\subsubsection{Putting it together}

We can now verify that presuppositions of SUP are met by this comparison class and assign a denotation to the most. The superlative's requirement that there be more than one element in the set is satisfied in (71). The other presupposition of SUP is that everything in the comparison class can be mapped to some degree by the quantity word that it combines with. This is what forces the dimension parameter of the Mon head to be matched to that of many. For any other value of the parameter, the superlative will be undefined. ${ }^{17}$

With the comparison class valued as in (71), the superlative measure DP has the following denotation:

17 The word most itself is ambiguous as the superlative of both underspecified much and cardinal many. In principle, then, any dimension that meets the monotonicity requirement will do, as long as there is convergence on a single dimension that satisfies presuppositions of both SUP and Mon. 

picked, the unique one that contains all the others.'

When this argument is fed back into the ordinary value of the clause, then the truth conditions of the NP-internal relative reading are returned. In (73), $\imath \mathrm{I}$ stands in for the referent of (72).

$$
\exists x_{e} \cdot * \text { green apple }(x) \wedge \operatorname{picked}(x, \mathrm{a}) \wedge\left[\lambda d . d \leq \mu_{\text {DIM }}(x)\right]=\imath \mathrm{I}
$$

In our scenario, Ayşe picked 7 apples of color A and smaller quantities of apples of other colors. If color A is green, then the sentence is true, because the largest interval in the comparison class does equal the measure of some green apples that Ayşe picked. If color A is red or golden, etc. then the sentence is false, because Ayşe did not pick a quantity of green apples whose measure equals that interval.

In section 5 we will see that the upstairs de dicto relative reading of quantity superlatives can also be derived on this in situ approach. Here I will point out that it gives us external relative readings of quantity superlatives as well as internal ones. If the focus is switched from green to Ayşe, $C$ will contain intervals that represent the maximal measures corresponding to green apples picked by her and green apples picked by each alternative person. It will be true just in case the largest of those intervals is the one representing the measure of green apples that Ayşe picked.

It is worth noting that, because the superlative will always return a singleton set containing the largest interval, the function of the definite article is essentially reduced to that of an iota-operator. Recall the claim by Szabolcsi (2012) that bare most can give rise to relative readings in a sentence like (13): AYŞE picked most green apples. To the extent that this is true for some speakers, it might be accounted for if the relative emptiness of the definite article's semantics in this context provides an acceptable environment for elision for those speakers.

\subsection{Adjectival superlatives revisited}

The proposal outlined above generates the elusive NP-internal relative readings of most, least and fewest. It makes use of the SUP-in situ derivation which requires movement of a definite-marked DP-constituent, but no extraction from within such a constituent. This derivation is possible because quantity superlatives are not merged directly with the substance NP, but instead are merged within a covert measure pseudopartitive structure higher up in the tree. Importantly, non-q-adjectives have different semantics from quantity words. As I show in what follows, this means that ordinary adjectival superlatives cannot participate in the construction that gives rise to NP-internal relative readings in English. 
The tree in (74) illustrates my conventional assumptions about the syntax of superlative adjectives. With a focused constituent inside the modified NP, this configuration cannot generate a relative reading, because neither a SUP-movement nor a SUP-in situ derivation of such a reading can succeed.

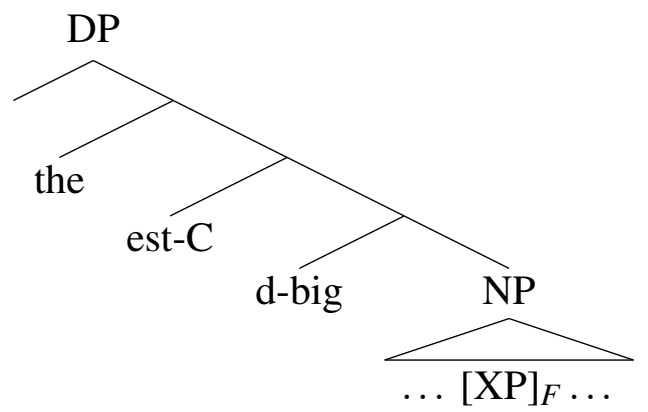

On Pancheva \& Tomaszewicz (2012)'s account, the movement derivation fails because the superlative morpheme in the configuration shown in (74) is not able to extract past the definite article which creates an island for degree-operators. Alternatively, on Shen $(2014,2015)$ 's account, it is not able to do so because the focused XP must have already covertly raised through the edge of the phase. So the only possible derivation is one in which the superlative is interpreted inside the DP constituent.

This SUP-in situ derivation requires that the comparison class argument be valued by focus association. For this to succeed, the focus operator must be merged in a position where it is discontinuous with $\mathrm{C}$, yet still scopes over the focused element. And whenever the focus element is internal the DP that contains the superlative adjective itself there is no such position in which the operator may be merged.

In the previous section I have proposed a very different syntactic configuration for the most NP, one which includes a silent Mon head and a type-flexible denotation for SUP and the definite article. Let us verify that this pseudopartitive measure structure cannot be 'exploited' to generate an NP-internal reading for non-q-superlatives. It should be clear that there is no position in the MonP structure for an adjective of type $\langle d,\langle e, t\rangle\rangle$. The superlative and definite article might combine directly with such an adjective (as is likely the case when superlative adjectives appear as predicates in copular constructions) to create a constituent of type $e$, or a shifted constituent of type $\langle\langle e, t\rangle, t\rangle$. But the biggest as such cannot replace the most of type $\langle d, t\rangle$ in the specifier of MonP. The open argument of Mon' can only be filled by a constituent of type $\langle d, t\rangle$ or a trace thereof. In section 4 I will discuss an exceptional case, where such an adjective is apparently coerced into a predicate of intervals due to its position in an overt measure structure. We may assume that absent such explicit cues a coerced interpretation is not possible. 
Another possible route, which suggests itself especially with analytic superlatives like the most intelligent is that the interval-denoting constituent the most could merge directly with the adjective inside the DegP. Here the distinction between intervals and degrees is crucial. The adjective has an open degree argument, but this cannot be saturated by a definite interval. The trace of much (type $\langle d,\langle d, t\rangle\rangle$ ) may do so (see Solt 2011, 2015) but the full measure DP cannot.

In short, the account proposed here explains the fact that NP-internal relative readings are not available for non-q-superlatives, as well as the fact that these readings are available for the most, the fewest and the least. It does so with a modified version of Schwarzschild (2006)'s MonP projection, in combination with a SUP-in situ approach to relative readings. This makes use of the focus-association mechanism of Rooth (1985) as first proposed by Heim (1999). Thus, all of the elements of the proposal are based on fairly conventional assumptions, the main innovation being that the definite article itself is type-flexible. This follows from the observation that due to its semantics, the definite article presupposes that the property of the NP it merges with is based on entities with mereological structure. Properties of scalar intervals satisfy this requirement.

\section{Two apparent problems}

\subsection{Superlatives inside overt measure pseudopartitives}

In certain special cases, adjectives of size do appear to have interval-modifying semantics just like quantity words. On the assumption that 'unit' nouns denote intervals, I so far predict that adjectives should not be able to modify these. However, it seems to be the case that adjectives occasionally appear inside measure phrases as attributive modifiers of such measure nouns, as in (75).

(75) a. Three generous spoonfuls of brown sugar was all the sweetener I added.

b. That's about two small handfuls of walnuts.

Presumably, the overt measure pseudopartitive structure allows the adjectival meanings to be coerced in this way. My analysis predicts a relative reading parallel to the NP-internal relative readings of q-superlatives in these just instances, and that prediction is born out. In the survey described in section 2, almost all respondents (15/18) judged the sentences in (76) true in the appropriate contexts, regardless of their dialect.

(76) a. John added the most generous spoonfuls of BROWN sugar.

b. Maria ate the smallest handful of WALNUTS. 
The constituency of the superlative measure DP can be demonstrated by topicalization. The sentences in (77) are grammatical, indicating that not only the adjective, but also the definite article forms a constituent with the measure noun. This provides additional evidence that the definite article in English can form part of a measure phrase, picking out intervals rather than individuals.

(77) a. The most generous spoonfuls, he added of BROWN sugar.

b. The smallest handful, she ate of WALNUTS.

Topicalization of the measure DP serves to strengthen the focus within the substance NP, facilitating the 'substance-internal' relative reading. These sentences lend themselves to a relative reading generated by focus internal to the substance NP. The most salient reading of (77a) is that the person in question used a more generous-sized teaspoon of brown sugar than of any other sweetener. Likewise, (77b) is true just in case the person ate a smaller handful of walnuts than she did of any other type of nuts.

The evidence from superlative-modified measure nouns lends additional support to the analysis presented here. Normally adjectives modify NPs directly as degree predicates of individuals, and hence their superlatives cannot generate relative readings based on focus internal to the NP itself. In those exceptional cases where adjectives instead appear inside of a measure pseudopartitive structure as degree predicates of intervals, they can occur and the equivalent of an NP-internal relative reading of their superlatives can be generated.

\subsection{Syntactic constraints in English}

For those speakers of English who find the NP-internal relative reading of quantity superlatives natural, there are nevertheless some linguistic constraints on its availability. One factor is prosody-the interpretation is highly sensitive to the locus of pitch-accent in the sentence. In this respect it is like constructions with only and other focus-sensitive operators. Another factor is the argument position of the superlative-containing DP. The contrast between (78) and (79) shows that there is a significant subject-object asymmetry for NP-internal relative readings.

(78) The program accepted the most AMERICAN students.

'The program accepted more American students than students of any other nationality.' 
The most, the fewest and the least

(79) ?? The most AMERICAN students enrolled in the program.

'More American students than students of any other nationality enrolled in the program'

This is reminiscent of the asymmetry that has been observed for overt Whmovement in English. While movement of a Wh-word out of a DP is generally allowed, questions that are formed by extraction of an argument from within a subject are significantly degraded. Compare (80a) with (80b):
a. Of whom did John's sister buy a picture?
b. ?? Of whom did a sister buy the picture?

We may hypothesize that the construction in (79) is infelicitous for the same reason that (80b) is. Where overt movement out of subjects is barred, so is covert movement. I have argued that the derivation of the NP-internal relative reading depends on covert extraction of the interval-denoting DP out of the larger nominal phrase. The unacceptability of such constructions when the nominal phrase is in subject position, as in (79) is therefore not unexpected.

If this is the correct explanation for the infelicity of NP-internal focus, then we can make a further prediction. Chomsky (2008) observes that Wh-movement out of passive subjects is much more acceptable than out of active subjects. Notice that (81) which is the passivization of (80) is much better than the example above with extraction out of an agentive subject.

? Of whom was a picture bought at the auction?

If the infelicity of the NP-internal relative readings of superlative-modified subjects is due to general constraints on movement, then the construction should be improved for subjects of passive sentences. As predicted, the passive counterpart to (78), where the most AMERICAN students becomes a subject is much better than (79) and it clearly has the NP-internal relative reading:

(82) ${ }^{?}$ The most AMERICAN students were accepted by the program. 'More American students than students of any other nationality were accepted by the program.'

The ban on extraction from adjuncts is robust, both within English and across languages (Stepanov 2007). As expected, the NP-internal relative reading is not possible when the quantity superlative appears inside an adjunct: 
?? The students attended programs in the most EUROPEAN countries. \#'The students attend programs in more European countries than in countries of any other continent.'

These judgements are subtle, and are complicated by the general sensitivity of the construction to prosody and context. However, the infelicity of the most NP in cases like (79) and (83) appears to have its source in more general linguistic constraints on movement out of subjects and adjuncts in English. ${ }^{18}$

\section{Revisiting the SUP-in situ versus SUP-movement debate}

This proposal depends on an in situ approach to derive the NP-internal relative readings of quantity superlatives. The superlative remains inside a DP constituent with many, and this entire constituent moves to allow the comparison class to be valued by association with a clause-level focus operator. Movement of this single constituent out of the larger DP through the phase edge is possible, but I assume (following Shen (2014)) that double extraction is not. For this reason, a derivation which involves movement of both the superlative morpheme and an NP-internal focused element is never available for either quantity or adjectival superlatives. In the absence of an alternative solution to the problem of these relative readings of quantity superlatives, therefore, the analysis proposed here provides indirect support for an in situ approach to relative readings in English in general. Let me be explicit about how far this support extends and what its limits are. I will show first that this approach can derive all of the attested relative readings of quantity superlatives including 'upstairs de dicto' readings. Then I discuss a possible extension to solve the problem of such readings for adjectival superlatives, but stop short of endorsing such an approach.

\section{1 'Upstairs de dicto' relative readings of quantity superlatives}

A type of relative reading that has been problematic for the SUP-in situ approach is what Heim (1999) dubbed the 'upstairs de dicto' reading. This is exemplified by the sentence in (84) as uttered in the following scenario: Individuals were asked to fill out a survey indicating the number of mountains that they want to climb. Of all the people surveyed, John gave the highest number.

18 For more on the the effect of movement constraints on the availability of NP-internal relative readings and related non-conservative readings of relative measures (cf. Ahn \& Sauerland (2017)) I refer the reader to this snippet: (Wilson 2019). 
(84) JOHN wants to climb the most mountains.

'The quantity such that John wants to climb at least that many mountains is greater than the quantity such that any other person wants to climb at least that many mountains.'

On a traditional in situ approach, with many given an adjectival treatment, this reading cannot be derived. Raising the DP the most mountains to take matrix clausal scope would result in the definite article picking out a specific plurality of mountains, but John's desire is not linked to any such entity. Leaving the DP below the scope of the modal verb would generate the meaning that John's desire is to climb a greater number of mountains than any other relevant person. This is a possible reading, but it not the intended one. On the upstairs de dicto reading, John may be indifferent to other climbers' achievements.

The approach I have proposed in the previous section does not run into these problems. The measure DP containing the superlative can take scope above the modal verb, while existential closure over the set of mountains remains low. Meanwhile the definite article picks out a specific interval, but not a specific individual. The LF of the IP that the superlative DP re-merges with is shown in (85).

$$
\sim \mathrm{S}\left[1\left[\left[\mathrm{Max}_{1}\right]\left[I_{P} \mathrm{John}_{i} \text { needs }\left[{ }_{I P}\left[{ }_{D P} \mathrm{D}_{\exists} \mathrm{t}_{1} \text { Mon mtns }\right] 2\left[\mathrm{PRO}_{i} \text { climb t }_{2}\right]\right]\right]\right]\right]
$$

This composes such that the ordinary value of IP is given by the formula in (86).

$$
\begin{aligned}
& \lambda I . I=\max \left(\lambda I \left[\text { need }_{w 1}(P)(\mathrm{j}) \wedge P=\left[\lambda w \left[\exists x .{ }^{*} \operatorname{mountain}_{w}(x) \wedge \operatorname{climb}_{w}(x, \mathrm{j}) \wedge\right.\right.\right.\right. \\
& \left.\left.\left[\mathrm{M}_{\#}(x)=I\right]_{w}\right]\right)
\end{aligned}
$$

'The set of intervals that corresponds to the maximal measure of mountains that John climbs in all of the words satisfying his desires.'

The comparison class is based on substitution of relevant alternatives to John, so it will consist of the maximal interval for each individual such that that person climbs some mountains measuring that quantity in all of their desire worlds. In other words, it will contain all of the the singleton sets with the intervals corresponding the the numbers people indicated on their surveys. The largest one of these intervals will be the referent of the superlative DP, and this is fed back into the formula in (86). The 'upstairs de dicto reading is achieved through an in situ style derivation.

I predict that there should also be an 'upstairs de dicto' reading with NP-internal focus, and this is the case. In a scenario where Ayşe is picking apples for a pie that calls for 10 green apples, 5 red apples and 3 yellow apples, it would be accurate to utter (87). 
(87) Ayşe needs to pick the most GREEN apples.

'The number such that Ayse needs to pick at least that many green apples is greater than the number such that she needs to pick at least that many apples of any other kind'

\section{2 'Upstairs de dicto' readings of non-quantity superlatives}

It is tempting to try to extend the analysis in (85) and (86) to cover all cases of upstairs de dicto readings in English. This would obviate the need for a movement derivation of relative readings for adjectival superlatives and allow for a unified treatment of the definite article. The classic example with an adjectival superlative is from Heim (1999):

(88) JOHN wants to climb the highest mountain.

'The height, such that John wants to climb at least that high of a mountain is greater than the height such that any other person wants to climb at least that high of a mountain.'

It is clear that what is being compared is measures of height, rather than actual mountains, and this is exactly what the pseudopartitive structure with the Mon head supplies. Perhaps the type-shifted denotations of adjectives discussed in section 3.4.2, where adjectives modify intervals rather than individuals, can be exploited to derive the reading in (88).

However, there is reason to be wary of such a move. I have demonstrated in section 3.4.2 that adjectives may exceptionally function as degree-modifiers of scalar intervals when they appear with measure nouns inside an overt pseudopartitive structure. If we assume that it is possible for an adjective to do so in the absence of any measure noun, then it is difficult to account for the absence of NP-internal relative readings for these superlatives. The presence of the modal verb would have to somehow trigger this type shift in the adjective. Pending any independent evidence for such triggering, I assume the interval-based approach applies only to quantity superlatives. One possible solution is to revisit the alternative non-movement approach to the upstairs de dicto readings proposed by Sharvit \& Stateva (2002). While this has been rejected by some due to the fact that it requires a non-standard denotation for the definite article, the idea that the is type-flexible and may pick out a unique property, rather than a unique individual (or scalar interval) is quite compatible with the current proposal. I leave the integration of this approach to future work. 


\subsection{Summary}

The analysis proposed here is able to account for all relative readings of quantity superlatives in English. The various NP-internal and NP-external relative readings and even the elusive 'upstairs de dicto' reading of quantity superlatives fall out straightforwardly from treating the most as a superlative measure DP. While this SUP-in situ approach provides an account for the absence of NP-internal relative readings for English non-quantity superlatives, it is not clear that it can simultaneously account for the availability of upstairs de dicto readings of such superlatives. On the other hand the SUP-movement approach, which can generate the upstairs de dicto readings, cannot generate NP-internal relative readings in a DP-language. The fact that there is a split in the interpretive possibilities for quantity and non-quantity superlatives in English therefore lends support to the in situ approach for definitemarked DPs across the board. An in situ approach to upstairs de dicto readings of non-quantity superlatives is therefore to be preferred for DP-languages and I refer to reader to Sharvit \& Stateva (2002) for one such account.

\section{Beyond English}

In this section I first tackle the problem of the difference between Bulgarian and English. I then introduce evidence that the construction we have been investigating exists in some varieties of Dutch, providing additional evidence for the syntactic constituency of the definite article and q-superlative that is at the heart of this proposal.

\subsection{Bulgarian}

An important question remains with respect to the differences in availability of these relative readings in Bulgarian and English. This proposal basically leaves intact Shen (2014, 2015)'s explanation for the availability of NP-internal readings for indefinite adjectival superlatives in Slavic languages, and I have argued based on Talić (2020) that this account can be extended to Bulgarian as an intermediate NP/DP-language. In the absence of definite-marking, the NP-internal relative reading is derived by SUP-movement. Extraction of both the focused NP and the superlative morpheme is possible in this case. When the DP containing a non-q-superlative such as naj-mladi ('youngest') is definite, just as in English the SUP morpheme cannot extract, so only NP-external relative readings derived by focus association in situ are possible. The SUP-in situ derivation fails when focus is inside the superlative-modified NP because there is no appropriate position for a focus operator to merge. However, the 
question remains why Bulgarian does not allow NP-internal relative readings for definite-marked quantity superlatives such as naj-mnogoto (the most).

Prima facie, my account predicts that NP-internal relative readings should be available for q-superlatives in DPs with definite marking in Bulgarian just as in English. However, the empirical evidence is that quantity superlatives in Bulgarian pattern with adjectival superlatives: only in the absence of definite-marking are NP-internal relative readings possible. The datum illustrating this is repeated here:
(11) Ivan se
zapozna $\mathrm{s}$
naj-mnogo-to ${ }^{20}$ studenti
ot LONDON
Ivan REFL met
with SUP-many-DEF student.PL from London.
\#'Ivan met more students from London than he did from any other city.'

One possible explanation for the failure of definite-marked naj-mnogoto NP to generate NP-internal relative readings is that Bulgarian mnogo and malo are in fact more like non-quantity adjectives than their English counterparts: predicates of individuals rather than of scalar intervals. If the Slavic quantity words have the adjectival denotations that Pancheva \& Tomaszewicz (2012) ascribe to them (of type $\langle d,\langle e, t\rangle\rangle$ ), then their patterning with non-quantity adjectives would be unsurprising. If this were the case, however, we would expect them to be more like non-q-adjectives in other respects. For instance, they should be compatible with non-monotonic measure interpretations, and they should show phi-feature agreement with the noun, contrary to fact. ${ }^{21}$ I therefore assume that in Bulgarian and other Slavic languages quantity words such as mnogo/malo are also degree predicates of intervals and a similar covert-pseudopartitive structure is involved. As I argue below, the difference, in the case of Bulgarian definite-marked q-superlative expressions is the merge position of the definite article.

The phenomenon of NP-internal relative readings provides additional empirical evidence that quantity superlatives in Slavic languages, including Bulgarian, are higher in the extended NP than non-q-superlatives. Shen (2014) observes that in Polish and other 'NP languages', relative readings are possible for a wider range of NP-internal focus constituents with quantity superlatives than with ordinary adjectival ones. Recall the evidence in section 2.3 that the NP-internal relative reading with focus on the noun-complement is blocked in NP-languages because anti-locality prevents extraction from this position when NP is a phase. I have shown that this also true for indefinite non-q-superlatives in Bulgarian (the relevant example is repeated in (89)). But when the adjective is replaced by a quantity superlative, Shen observes that the NP-internal relative reading becomes available with focus on

21 As discussed by Coppock et al. (2020), this would also predict the availability of proportional ('more than half') readings of naj-mnogo which are in fact absent in Bulgarian. See also Pancheva (2015). 
the noun complement in Polish. And this is also the case for Bulgarian according to my informants, who find the paraphrase given for (90) quite natural.

(89) Ivan poznava naj-inteligentni učenitsi po [biologija $]_{F}$.

Ivan knows SUP-smart.PL students of biology.

\#Ivan knows smarter students of biology than students of other subjects.

(90) Ivan poznava naj-mnogo učenitsi po [biologija $]_{F}$.

Ivan knows SUP-many students of biology.

Ivan knows more students of biology than students of other subjects.

According to Shen, this asymmetry show that nominals containing q-superlatives contain at least one functional layer above the minimal NP, providing an intermediate landing place for the noun complement to extract through without violating antilocality. On the one hand, the presence of an extra layer follows if adnominal q-adjectives in Slavic, just as in English, involve a MonP layer. On the other hand, if this is the case then the specifier of MonP is already occupied by that q-adjective, so it is unavailable as a landing site for complement extraction.

Therefore, I propose that in Slavic, just as in English, NP-internal relative readings of q-superlatives are derived not by raising of the superlative morpheme (the movement derivation), but by focus-association in situ, with raising of the entire q-superlative constituent from Spec MonP. It is straightforward how this would work in a language like Polish which has no definite articles: the shift of the measure phrase constituent from a singleton set of intervals of type $\langle\langle d, t\rangle, t\rangle$ to a unique interval, type $\langle d, t\rangle$, that in English is accomplished with the morpheme the, is instead achieved by the iota type shift that is generally assumed to be available in NP-languages (generalized to instantiate a shift from type $\langle\langle d, t\rangle, t\rangle$ to $\langle d, t\rangle$ ).

As for Bulgarian, I have argued above, building on work by Talić (2020), that with respect to the NP/DP parameter Bulgarian is an 'intermediate' language. An overt determiner signals the presence of a DP layer and given the coexistence of DP and NP arguments in the language, and the role of overt articles in signaling the former, it makes sense that Bulgarian speakers parse this as a D-head in the extended projection of the overt noun, rather than as part of the measure phrase constituent. The definite-marked DP in (11) is thus parsed with with the structure in (91), which is only interpretable via focus association with an NP-external element: 
(91)
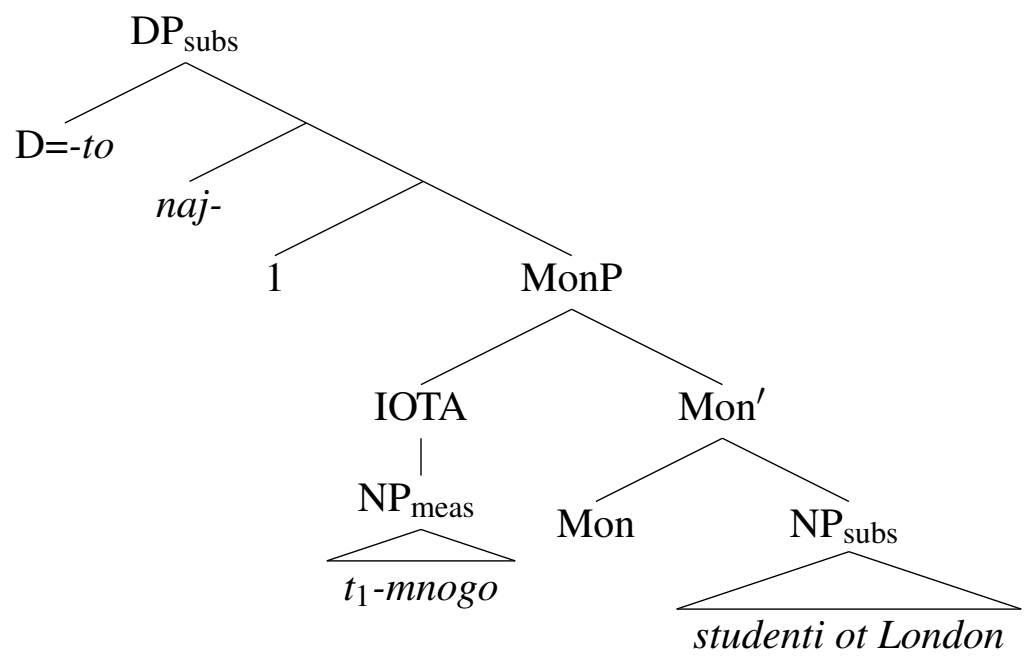

NP-internal readings, then, are generated using the same derivation as we have proposed for English, but with the measure phrase naj-mnogo iota-shifted rather than containing an overt definite morpheme. These readings are not generated when -to is present because this has high scope in the substance DP which is thus semantically definite.

\subsection{Flemish}

Roelandt $(2013,2016)$ observes that Flemish Dutch has a construction which gives rise to the NP-internal relative reading of quantity superlatives. This is especially interesting because, due to the slightly richer agreement paradigm of Dutch articles, it provides additional evidence for the for the hidden structure that I have proposed here. In these constructions, the definite-marked quantity superlative fails to agree with the plural or mass noun, taking instead the neuter form as it does on its adverbial use. Yet, as with English the most NP, the interpretation is clearly comparison of quantities of the entity denoted by the substance NP, rather than of events or temporal intervals. The examples (92) and (93) below are from Roelandt (2013):

(92) Jan heeft het meeste platen van ZAPPA beluistered. Jan has the.N.SG most.AGR music.PL by Zappa listened.to 'Jan has listened to more records by Zappa than by any other band.'

Speakers of Northern Dutch judge the sentence in (92) to be ungrammatical. The article must agree with the plural, common-gender noun platen. The sentence in (93) with the agreeing determiner $d e$ is accepted by speakers of all varieties of Dutch, but 
it only has a majority reading of the quantity superlative (or the NP-external relative reading if the focus is shifted to the subject).

(93) Jan heeft de meeste platen van ZAPPA beluistered. Jan has the.CG.PL most.AGR music.CG.PL by Zappa listened.to a. \#'Jan has listened to more records by Zappa than by any other band.'

b. 'Jan has listened to the majority of records by Zappa.'

Importantly, Flemish patterns like English in that the non-agreeing construction that gives rise to NP-internal relative readings is only possible with quantity superlatives. The equivalent sentence in (94) is considered equally ungrammatical in Flemish and Northern Dutch, while the agreeing construction in (95) does not give rise to NP-internal relative readings.

*Jan heeft het beeste platen van ZAPPA beluistered. Jan has the.N.SG best.AGR music.PL by Zappa listened.to

(95) Jan heeft de beeste platen van ZAPPA beluistered. Jan has the.CG.PL best.AGR music.CG.PL by Zappa listened.to a. \#'Jan has listened to better records by Zappa than by any other band.' b. 'Jan has listened to the best records by Zappa (that exist).'

In order to explain the apparent failure to check phi features in (92), Roelandt (2013) proposes that the neuter determiner in the non-agreeing construction introduces a DP that is projected by a null NP. A silent noun within the measure DP is also posited by Wilson (2018).

The current proposal does without that extra covert element. I assume that the structure for Flemish het meeste is identical to that proposed for English the most on the derivation that yields an NP-internal relative reading (i.e., the proposal in section 3). The neuter singular is default agreement that is triggered in the absence of any nominal inside the measure DP to value the phi-features on the determiner. By contrast, Flemish (and Northern Dutch) de meeste is pronounced when the definite article is merged in the extended projection of the overt plural noun, just as I propose for Bulgarian. ${ }^{22}$ Hence, the Flemish dialect provides morphological evidence from a language closely related to English, in support of a structure generating NP-internal relative readings in which the determiner forms a constituent with the quantity superlative rather than being merged with the entire substance NP.

22 Recall that the 'agreement' in Bulgarian is phonologically triggered (cf. fn 3), while Dutch has true syntactic agreement on determiners. 
The Flemish/Northern Dutch split is also informative with respect to the variable acceptability of the construction for speakers of English. It suggests that this interspeaker variation may be based on a genuine micro-parameter of the grammar. It hinges on whether or not an overt determiner must be parsed as part of the extended projection of the overt noun it precedes. The setting of this parameter is clearly divided between Northern Dutch and Flemish, ${ }^{23}$ and Bulgarian patterns with Northern Dutch. The micro-parameter has a more scattered distribution within English.

\section{Conclusion}

In this paper, I have presented evidence that a kind of 'NP-internal relative' reading is available in some varieties of English and Dutch. This reading arises for just the quantity superlatives most, least and fewest (and their Dutch counterparts). While there is significant inter-speaker and cross-dialectal variation with respect to the availability of the readings which remains to be accounted for, in this paper I have focused on the evidence from those varieties that do allow the reading.

As the proposals that derive NP-internal relative readings in Slavic languages cannot be extended to these definite-marked constructions, I have proposed a novel syntax which places q-superlatives inside of definite measure DPs. This is supported by independent evidence in English and Dutch. The account for the phenomenon presented here lends support to models that treat quantity words as degree-predicates of intervals along the lines of Solt (2014) and Schwarzschild (2006). It further suggests that unlike themselves, intervals are in some sense individual-like - at least enough so to allow these predicates to be merged in DP measure phrases.

Another important conclusion is that the SUP-in situ derivation must be available to the grammar in order for quantity superlatives to generate relative readings from focus inside the NPs they modify. The SUP-movement derivation is needed to generate these readings for both q- and non-q-superlatives in NP-languages, but that derivation cannot generate the interpretations of definite the most, the fewest and the least for which I have provided an account here. The data and analysis presented here contribute to our understanding of the structure of the nominal domain and the nature of quantity adjectives. Future research into these and similar constructions in varieties of Germanic, Slavic and other languages can illuminate the nature of the microparameter that governs the availability of the construction in DP-languages, and the spectrum of variation between languages with respect to the DP/NP parameter.

23 Two speakers from the Brabants region provided the author with judgements that add an additional complication to the question of variation. For these speakers, the construction with NP-internal relative readings was only acceptable for mass NPs and not for plurals. 
The most, the fewest and the least

\section{References}

Ahn, Dorothy \& Uli Sauerland. 2017. Measure constructions with relative measures: Towards a syntax of non-conservative construals. The Linguistic Review 34(2). 215-248. https://doi.org/10.1515/tlr-2017-0001.

Barwise, Jon \& Robin Cooper. 1981. Generalized quantifiers and natural language. In Philosophy, language, and artificial intelligence, 241-301. Springer Netherlands. https://doi.org/10.1007/978-94-009-2727-8_10.

Bošković, Željko. 2008. What will you have, DP or NP? In North East Linguistics Society (NELS) 37 1, 101-114.

Bresnan, Joan W. 1973. Syntax of the comparative clause construction in English. Linguistic Inquiry 4(3). 275-343.

Buccola, Brian \& Benjamin Spector. 2016. Modified numerals and maximality. Linguistics and Philosophy 39(3). 151-199. https://doi.org/10.1007/s10988016-9187-2.

Bumford, Dylan. 2017. Split-scope definites: Relative superlatives and haddock descriptions. Linguistics and Philosophy 40(6). 549-593. https://doi.org/10. 1007/s 10988-017-9210-2.

Champollion, Lucas. 2015. Stratified reference: the common core of distributivity, aspect, and measurement. Theoretical Linguistics 41(3-4). 109-149. https: //doi.org/10.1515/tl-2015-0008.

Champollion, Lucas. 2017. Parts of a whole: Distributivity as a bridge between aspect and measurement, vol. 66. Oxford University Press. https://doi.org/10. 1093/oso/9780198755128.001.0001.

Chomsky, Noam. 2001. Derivation by phase. In Michael Kenstowicz (ed.), Ken Hale: A life in language, 1-52. Cambridge, MA: MIT Press. https://doi.org/10. 7551/mitpress/4056.003.0004.

Chomsky, Noam. 2008. On phases. In Foundational issues in linguistic theory: Essays in honor of Jean-Roger Vergnaud Current Studies in Linguistics (45), 133-166. Cambridge,MA: MIT press.

Coppock, Elizabeth \& David Beaver. 2014. A superlative argument for a minimal theory of definiteness. In Semantics and Linguistic Theory (WCCFL) 24, 177196. https://doi.org/10.3765/salt.v24i0.2432.

Coppock, Elizabeth \& David Beaver. 2015. Definiteness and determinacy. Linguistics and Philosophy 38(5). 377-435.

Coppock, Elizabeth, Elizabeth Bogal-Allbritten \& Golsa Nouri-Hosseini. 2020. Universals in superlative semantics. Language 96(3). 471-506. https://doi.org/ 10.1353/lan.2020.0039.

Cresswell, Max J. 1976. The semantics of degree. In Montague grammar, 261-292. Elsevier. 
Dost, Er \& Vera Gribanova. 2006. Definiteness marking in the Bulgarian. In West Coast Conference on Formal Linguistics (WCCFL 25), .

Embick, David \& Rolf Noyer. 2001. Movement operations after syntax. Linguistic Inquiry 32(4). 555-595.

Farkas, Donka F \& Katalin E Kiss. 2000. On the comparative and absolute readings of superlatives. Natural Language \& Linguistic Theory 18(3). 417-455.

Franks, Steven. 2001. The internal structure of Slavic noun phrases, with special reference to Bulgarian. In Generative linguistics in Poland: Syntax and morphosyntax, 53-69.

Hackl, Martin. 2000. Comparative quantifiers: Massachusetts Institute of Technology dissertation.

Hackl, Martin. 2009. On the grammar and processing of proportional quantifiers: most versus more than half. Natural Language Semantics 17(1). 63-98. https: //doi.org/10.1007/s11050-008-9039-x.

Heim, Irene. 1985. Notes on comparatives and related matters. ms., University of Texas, Austin .

Heim, Irene. 1999. Notes on superlatives. ms., Massachusetts Institute of Technology

Heim, Irene. 2000. Degree operators and scope. In Semantics and Linguistic Theory (SALT) 10, 40-64. https://doi.org/10.3765/salt.v10i0.2722.

Heim, Irene. 2002. On the projection problem for presuppositions. Formal Semantics: The Essential Readings 249-260. https://doi.org/10.1002/9780470758335. ch10.

Herdan, Simona \& Yael Sharvit. 2006. Definite and nondefinite superlatives and npi licensing. Syntax 9(1). 1-31. https://doi.org/10.1111/j.1467-9612.2006.00082.x.

Hoeksema, Jacob. 1984. Partitives. ms., University of Groningen 250.

Jackendoff, R. 1977. X syntax: A study of phrase structure Linguistic Inquiry Monographs (2). Cambridge, MA: MIT Press.

Kayne, Richard S. 2005. On the syntax of quantity in English. ms, New York University .

Kennedy, Christopher. 2001. Polar opposition and the ontology of 'degrees'. Linguistics and Philosophy 24(1). 33-70.

Kotek, Hadas, Yasutada Sudo \& Martin Hackl. 2015. Experimental investigations of ambiguity: the case of most. Natural Language Semantics 23(2). 119-156. https://doi.org/10.1007/s11050-015-9113-0.

Kotek, Hadas, Yasutada Sudo, Edwin Howard \& Martin Hack1. 2011. Most meanings are superlative. Syntax and Semantics 37. 101-145. https://doi.org/10.1163/ 9781780523750_005.

Krasikova, Sveta. 2012. Definiteness in superlatives. In Logic, language and meaning, 411-420. Springer. https://doi.org/10.1007/978-3-642-31482-7_42. 
Krifka, Manfred. 1989. Nominal reference, temporal constitution and quantification in event semantics. In R. Bartsch, J. van Benthem \& P. van Emde Boas (eds.), Semantics and contextual expression, 75-116. De Gruyter. https://doi.org/10. 1515/9783110877335-005.

Lønning, Jan Tore. 1987. Mass terms and quantification. Linguistics and Philosophy 10(1). 1-52. https://doi.org/10.1007/bf00603391.

Pancheva, Roumyana. 2015. Quantity superlatives: The view from Slavic and its cross-linguistic implications. In Annual meeting of the Chicago Linguistic Society (CLS) 49. Chicago: Chicago Linguistic Society, .

Pancheva, Roumyana \& Barbara Tomaszewicz. 2012. Cross-linguistic differences in superlative movement out of nominal phrases. In West Coast Conference on Formal Linguistics (WCCFL) 30, 292-302. Cascadilla Proceedings Project.

Roelandt, Koen. 2013. (The) most in Flemish Dutch: Definiteness and specificity. In Student sessions at the European Summer School in Logic, Language and Information, 214-232. Springer.

Roelandt, Koen. 2016. Most or the art of compositionality. Dutch de/het meeste at the syntax-semantics interface: University of Leuven dissertation.

Rooth, Mats. 1985. Association with focus: University of Massachusetts, Amherst dissertation.

Schwarzschild, Roger. 2002. The grammar of measurement. In Semantics and Linguistic Theory (SALT) 12, 225-245. https://doi.org/10.3765/salt.v12i0.2870.

Schwarzschild, Roger. 2006. The role of dimensions in the syntax of noun phrases. Syntax 9(1). 67-110. https://doi.org/10.1111/j.1467-9612.2006.00083.x.

Sharvit, Yael \& Penka Stateva. 2002. Superlative expressions, context, and focus. Linguistics and Philosophy 25(4). 453-504.

Shen, Zheng. 2014. On the relative readings with NP internal focus of superlatives. In West Coast Conference on Formal Linguistics (WCCFL) 31, 409-418. Cascadilla Proceedings Project.

Shen, Zheng. 2015. The third reading of the most expensive photo of Abby. University of Pennsylvania Working Papers in Linguistics 21(1). 29.

Solt, Stephanie. 2009. The semantics of adjectives of quantity: City University of New York dissertation.

Solt, Stephanie. 2011. How many most's? In Sinn und Bedeutung 15, 565-579. Saarbrücken: Saarland University Press.

Solt, Stephanie. 2014. Q-adjectives and the semantics of quantity. Journal of Semantics 32(2). 221-273. https://doi.org/10.1093/jos/fft018.

Solt, Stephanie. 2015. Measurement scales in natural language. Language and Linguistics Compass 9(1). 14-32. https://doi.org/10.1111/lnc3.12101.

von Stechow, Arnim. 1984. Comparing semantic theories of comparison. Journal of Semantics 3(1-2). 1-77. https://doi.org/10.1093/jos/3.1-2.1. 
von Stechow, Arnim. 2006. Times as degrees: früh(er) 'early(er)', spät(er) 'late(r)', and phrase adverbs. Unpublished manuscript.

Stepanov, Arthur. 2007. The end of CED? minimalism and extraction domains. Syntax 10(1). 80-126. https://doi.org/10.1111/j.1467-9612.2007.00094.x.

Szabolcsi, Anna. 1986. Comparative superlatives. In Papers in theoretical linguistics, vol. 8, 245-266. MIT Working Papers in Linguistics.

Szabolcsi, Anna. 2012. Compositionality without word boundaries:(the) more and (the) most. In Semantics and Linguistic Theory (SALT) 22, 1-25. https: //doi.org/10.3765/salt.v0i0.2629.

Talić, Aida. 2020. Affixal-article languages and structural parallelism in Slavic and beyond. In Current developments in Slavic linguistics. twenty years after:(based on selected papers from FDSL 11), Peter Lang.

Tomaszewicz, Barbara Maria. 2015. Superlative ambiguities: A comparative perspective: University of Southern California dissertation.

Wilson, E Cameron. 2015. Deriving the most internal relative reading. In Sinn und Bedeutung 20, 779-797.

Wilson, E Cameron. 2018. Amount superlatives and measure phrases: City University of New York dissertation.

Wilson, E Cameron. 2019. Constraints on non-conservative readings in English. Snippets 37. 114-115. https://doi.org/10.7358/snip-2019-037-wils.

E. Cameron Wilson

Berlin, Germany

ewilson2@gradcenter.cuny.edu 